\title{
The Destiny of Glucose from a MicroRNA Perspective
}

\author{
Paola Mirra ${ }^{1,2}$, Cecilia Nigro ${ }^{1,2}$, Immacolata Prevenzano ${ }^{1,2}$, Alessia Leone $^{1,2}$, Gregory \\ Alexander Raciti ${ }^{1,2}$, Pietro Formisano ${ }^{1,2}$, Francesco Beguinot ${ }^{1,2}$ and Claudia Miele ${ }^{1,2 *}$ \\ ${ }^{1}$ Istituto per l'Endocrinologia e l'Oncologia Sperimentale "Gaetano Salvatore" - CNR, Naples, Italy, ${ }^{2}$ Department of \\ Translational Medical Sciences, University of Naples Federico II, Naples, Italy
}

\section{OPEN ACCESS}

Edited by: Antonio Brunetti, Magna Græcia University, Italy

Reviewed by: Sinan Tanyolac, Istanbul University, Turkey Rodolfo Iuliano, Magna Græcia University, Italy

*Correspondence: Claudia Miele c.miele@ieos.cnr.it

Specialty section: This article was submitted to Genomic Endocrinology, a section of the journal

Frontiers in Endocrinology

Received: 15 December 2017 Accepted: 05 February 2018 Published: 26 February 2018

Citation: Mirra P, Nigro C, Prevenzano I, Leone A, Raciti GA, Formisano $P$,

Beguinot $F$ and Miele C (2018)

The Destiny of Glucose from a MicroRNA Perspective. Front. Endocrinol. 9:46. doi: 10.3389/fendo.2018.00046
Glucose serves as a primary, and for some tissues the unique, fuel source in order to generate and maintain the biological functions. Hyperglycemia is a hallmark of type 2 diabetes and is the direct consequence of perturbations in the glucose homeostasis. Insulin resistance, referred to as a reduced response of target tissues to the hormone, contributes to the development of hyperglycemia. The molecular mechanisms responsible for the altered glucose homeostasis are numerous and not completely understood. MicroRNAs (miRNAs) are now recognized as regulators of the lipid and glucose metabolism and are involved in the onset of metabolic diseases. Indeed, these small non-coding RNA molecules operate in the RNA silencing and posttranscriptional regulation of gene expression and may modulate the levels of kinases and enzymes in the glucose metabolism. Therefore, a better characterization of the function of miRNAs and a deeper understanding of their role in disease may represent a fundamental step toward innovative treatments addressing the causes, not only the symptoms, of hyperglycemia, using approaches aimed at restoring either miRNAs or their specific targets. In this review, we outline the current understanding regarding the impact of miRNAs in the glucose metabolism and highlight the need for further research focused on altered key kinases and enzymes in metabolic diseases.

\section{Keywords: glucose metabolism, insulin signaling, insulin resistance, microRNAs, posttranscriptional regulation}

The glucose metabolism provides the principal source of cellular energy and substrate storage. Indeed, although several other components can be used for fuel by muscles and other tissues in the fasted state, a continuous supply of glucose is necessary as a source of energy, especially for the cells of the nervous system and the erythrocytes, which have little or no capability of storing glucose and using other substrates as fuel. The maintenance of a normal glucose balance or homeostasis depends on several simultaneous ongoing processes in different tissues, including the liver, skeletal muscle, and adipose tissue, and it is under the control of insulin. Indeed, insulin is considered the principal hormone in the glucose homeostasis, suppressing hepatic gluconeogenesis and promoting glycogen synthesis and storage in the liver and muscle, triglyceride storage in the adipose tissue and amino acid storage in the muscle. Thus, in insulin-resistant conditions, a decrease in the blood glucose clearance occurs, while the hepatic glucose output and release in the plasma persist, contributing to the hyperglycemia, namely high glucose levels in the bloodstream (1). Un-treated chronic hyperglycemia is responsible for long-term complications.

The insulin signal transduction machinery has been explained in detail over the past few decades and the existence of molecular defects in the pathways activated by insulin, which contribute to metabolic disorders, are undeniable (2). However, the etiology of type 2 diabetes (T2D) is polygenic 
and heterogeneous, combining both genetic and environmental factors (3-5). Moreover, considering the delay between the onset and the diagnosis of T2D, which is often made clinically when complications are already manifest, it becomes necessary to engage in further investigations to establish other main causes of the disease for an early and more accurate prediction of high-risk individuals and for the identification of new therapeutic targets. From this perspective, in addition to the insulin signaling, it is crucial to consider also metabolic pathways in this search, examining key metabolic regulators and coordinators that may have a role in the onset of hyperglycemia.

To date, most studies have been concentrated on the transcriptional regulation mechanisms or posttranslational modifications of insulin signaling components or metabolic enzymes. By contrast, a conceptual gap exists regarding the role of posttranscriptional gene silencing by microRNAs (miRNAs) in the control of the energy metabolism in healthy as well as in obese and T2D individuals. The pressure to close this gap is due to mounting evidence that suggests a prominent role for miRNAs in the metabolism and metabolic disorders (6), in addition to the challenge currently facing scientists in the proposal of new therapeutic targets against hyperglycemia and T2D.

The purposes of this review are as follows:

- to highlight the recent progress in the study of miRNAs involved in the metabolism, with a special emphasis on metabolic abnormalities in insulin-resistant conditions;

- to report persistent limitations in the study of miRNAs involved in the glucose metabolism.

\section{INTRODUCTION ON miRNAs}

MicroRNAs are small (20-22 nucleotides), non-coding RNAs, characterized by an evolutionary conservation and able to regulate gene expression at the posttranscriptional level. In more detail, the miRNA seed region interacts with the complementary sequence in the $3^{\prime}$ untranslated region (UTR) of target messenger RNAs (mRNAs) and, subsequently, inhibits the translation or targets the degradation of the bound mRNAs (7). The miRNA biogenesis includes several steps: transcription, primary transcript (pri-miRNA) processing, transport to the cytoplasm, precursor miRNA (pre-miRNA) processing, and strand selection (8). This rigorous, multi-step process ensures that only those miRNAs with the correct structure and sequence are functional $(9,10)$.

Regarding transcription, miRNA genes are found in every chromosome, and miRNA promoters, like protein-coding genes, are regulated by epigenetic mechanisms and transcription factors. The complete definition of the gene structure is ongoing for all the identified miRNAs, as the genomic location and the gene-neighborhood context may be informative about specific miRNAs and miRNAs in general. miRNA genes are transcribed by RNA polymerase II or III from independent miRNA genes (intergenic) or from the exons or introns in transcription units of protein-coding or non-coding genes (intragenic). The intronic miRNAs are more common and better studied, showing a coordinated expression with the host gene. miRNA genes are frequently clustered in the genome and simultaneously transcribed into single poly-cistronic transcripts to realize an intricate regulatory network, being expressed at similar levels and in a coordinated manner. The intriguing aspect of the miRNA clusters is that they frequently contain representatives from different miRNA families, meaning that the members of a given cluster are able to regulate multiple different mRNAs. This feature is important because it implies that the regulation by miRNAs is extremely complex, involving several signaling pathways and gene networks. However, the transcriptional regulation of miRNAs, which represents the critical step in modulating their expression, remains poorly understood. This is due to limitations in the methodology available to study pri-miRNAs and in the characterization of their promoter regions. Therefore, it is necessary to identify the factors that control the transcription of specific miRNAs to suggest novel therapeutic strategies aimed at restoring the aberrant miRNA expression rather than treating their consequences.

The nascent transcript, referred to as the pri-miRNA, is usually several hundred nucleotides in length and contains one or more hairpin structures. The miRNA-specific processing begins in the nucleus with the cleavage at the stem-loop formations by an RNase III-like enzyme, known as Drosha, which acts in concert with co-factors, including DiGeorge syndrome critical region 8 (also known as Pasha in flies and nematodes), at the level of the Microprocessor complex. The result is a 70-nucleotide long stemloop precursor, known as the pre-miRNA, which is then exported to the cytosol by exportin 5 and Ran-GTP through nuclear pores. Once in the cytoplasm, Dicer, another RNase III-like endonuclease, recognizes the hairpin-shaped pre-miRNA hairpin and cuts the terminal-loop to generate a RNA duplex, 20-22 nucleotides in length. To stabilize the interaction of Dicer with the pre-miRNA, the Dicer cleavage takes place in a large complex, which includes TRBP or TARBP2 (the human immunodeficiency virus transactivating response RNA-binding protein).

The resulting miRNA duplex is composed of the mature miRNA and the base-paired passenger strand, sometimes indicated as the miRNA* strand. The final step consists in the incorporation of the miRNA duplex into the final effector complex, namely the RNA-induced silencing complex (RISC), where it is loaded onto an Argonaute (Ago) protein. At this point, the strand that exhibits less stable base pairing at the $5^{\prime}$ end remains associated with the Ago protein (mature miRNA), while the other is unwound from the duplex and typically degraded by the RISC (miRNA* strand), although some miRNAs ${ }^{*}$ are thought to regulate gene expression like mature miRNAs. However, it is not known why some miR$\mathrm{NAs}^{*}$ are functional and others are not. One hypothesis is that the two strands are used differently in response to extracellular or intracellular signals, regulating diverse sets of protein-coding genes as needed; an alternative hypothesis is that the working strand could be selected in a tissue-specific manner (10-17).

It has been estimated that approximately $60 \%$ of proteincoding genes are influenced by miRNAs (18). In addition, recent advances in bioinformatics and biochemical methods for the study of miRNAs are currently allowing the identification and validation of a growing number of targets, strengthening the functions of miRNAs $(19,20)$. Indeed, they are involved in many key biological processes. As a consequence, their aberrant expression may be responsible for several pathophysiological 
conditions, suggesting that miRNAs could serve as novel targets for preventive or therapeutic interventions. However, since a single miRNA has rather a modest effect on the protein levels of specific targets, multiple concurrent actions on functionally related targets are necessary to observe a noteworthy effect due to this specific miRNA, which is possible as it targets hundreds of genes. In addition, multiple miRNAs may act in concert to exert a more potent additive effect on one specific mRNA target, as multiple miRNA binding sites are predicted in its $3^{\prime}$ UTR.

\section{THE RELEVANCE OF miRNAs IN THE METABOLISM}

In the past few decades, miRNAs have emerged as key regulators of different aspects in development, homeostasis, and function $(21,22)$. In addition, their importance in the control of the metabolism has also been revealed, as miRNA research in the metabolic field has progressed rapidly in the recent years (23).

At the present time, however, only a handful of miRNAs have been identified as capable of mediating adipocyte differentiation and function $(24,25)$, controlling $\beta$ cell mass and insulin secretion $(26,27)$ and co-targeting multiple nodes in the insulin signaling pathway (28) at the level of the skeletal muscle, adipose tissue, and liver (29). Moreover, for the identified miRNAs, only a few important targets have been clearly defined, while most miRNA targeting remains undisclosed.

Nevertheless, it is now indisputable that an aberrant expression and function of miRNAs contribute to the loss of the glucose homeostasis, leading to pathogenic conditions $(30,31)$. Therefore, to assess the involvement of miRNAs in T2D, most research efforts have addressed the expression profile of miRNAs mainly in animal models and, to a lesser extent, in diabetic patients. Although changes in miRNA expression levels have been demonstrated in humans, it is not possible to gain a clear picture at the moment, considering the limited available data and important drawbacks, such as the small cohort size and confounding factors related to age, body mass index, and sex differences, in addition to the lack of uniformity in miRNA measurement techniques (32).

Several promising studies have demonstrated that the manipulation of specific miRNAs in vivo, mostly in the liver, can modulate metabolic phenotypes and even reverse the course of insulin resistance and diabetes (33), suggesting that miRNA-based approaches may represent a viable strategy for treating metabolic diseases in the future $(34,35)$. However, more knowledge is needed on current obstacles ranging from inadequate delivery strategies to possible side effects.

Furthermore, it has been demonstrated that circulating miRNAs are detectable and stable in body fluids and that altered circulating miRNA profiles are associated with metabolic diseases, including T2D (36). For this reason, circulating miRNAs show great promise as novel biomarkers for such disorders and/or their associated complications. This aspect will be especially useful in the case of T2D (37), which is currently screened for and diagnosed by reliable biological tests based on blood glucose levels, but lacks of the means to detect at-risk patients or to monitor diabetic complications. Therefore, the availability of easily detectable biomarkers able to identify subjects who are in the early, pre-clinical stages of T2D or who are destined to suffer from it, in addition to monitoring the progression of diabetic complications and the response to treatments, may allow the implementation of personalized therapies. However, the studies performed to date are insufficient to warrant application of circulating miRNAs in clinical practice, proving to be highly heterogeneous in size and inclusion criteria, and not replicable. Hence, several key issues need to be addressed, before they can be used as biomarkers. A major challenge is to establish robust protocols for pre-analytical sample handling, miRNA extraction, and measurement, which are all important for the reproducibility of the results. Additionally, planning studies need to be conducted using well-characterized and larger cohorts to gain sufficient statistical power. Finally, sets of miRNAs characterizing the various metabolic diseases are more preferable rather than single miRNAs to be used as biomarkers to increase the specificity of the analysis.

\section{THE DIRECT AND INDIRECT EFFECTS OF miRNAs ON THE INSULIN SIGNALING PATHWAY}

Insulin, interacting with a specific tyrosine kinase receptor, propagates signals via two main branches: the phosphatidylinositol 3-kinase (PI3K)-AKT/protein kinase B (PKB) pathway, which is responsible for most of the metabolic effects of the hormone, and the RAS-mitogen-activated protein kinase pathway, which regulates gene expression and controls proliferation, differentiation, and survival at the cellular level. Therefore, the insulin signal transduction must be tightly controlled to avoid severe metabolic and proliferative perturbations. To ensure a proper signal duration and intensity, negative regulators depend on insulin itself. These feedback mechanisms, based on the action of phosphatases or inhibitory proteins, turn off the insulin signal in a rapid manner at different, essential sites. Among the hundreds of molecules involved in the insulin signaling pathway, the insulin receptor (IR)/insulin receptor substrate protein (IRS) interaction, the PI3K heterodimer and AKT/PKB have been identified as critical nodes (38). However, some of the inhibitory mechanisms on these nodes can be altered in pathophysiological conditions, participating in the development of insulin resistance and, in turn, contributing to the metabolic abnormalities in insulin-sensitive cell types, namely adipocytes, hepatocytes, and myocytes (2). A large number of studies have demonstrated defects in a myriad of processes, often concomitantly, in various tissues and cell types. Nevertheless, as the causes of the reduced responsiveness to insulin are numerous and multifactorial, deciphering the complexity of the insulin resistance pathogenesis remains one of the great challenges on the way toward developing new molecules for a more effective treatment of T2D and associated diseases.

Furthermore, determining whether and how changes in miRNA levels have a causative effect in the onset of insulin resistance is also under investigation. Several studies have identified miRNAs as regulators of key components of the insulin signaling, contributing to their downregulation in insulin-resistant conditions, and they are shown in Figure 1 and Table 1. However, well-known molecular mechanisms, able to negatively regulate 


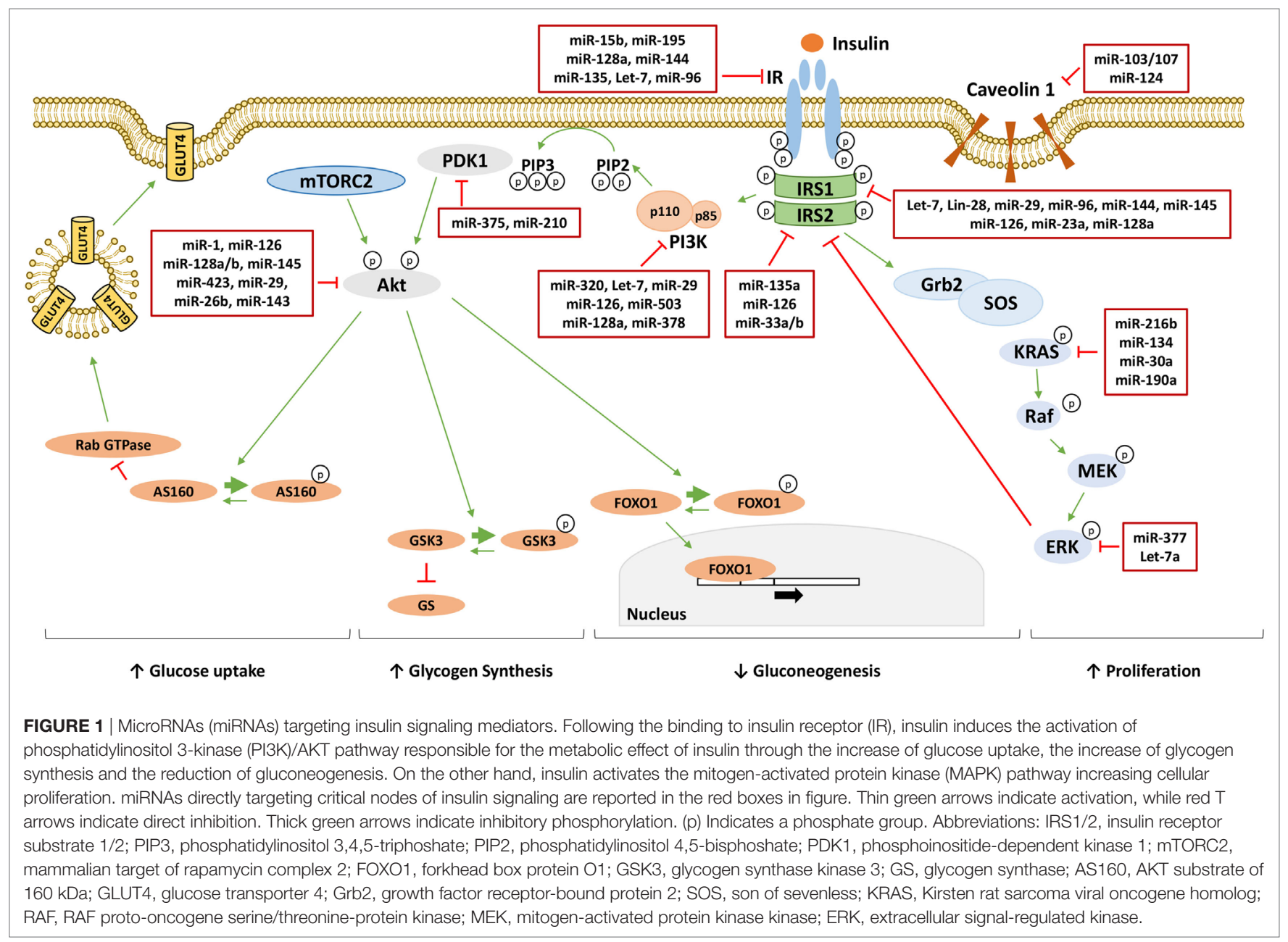

the critical nodes of the insulin signaling, may also be modulated by miRNAs. Hence, miRNAs may also affect indirectly the activity of these nodes through their negative regulators. Examples are shown in Figure 2 and are made explicit in the text below.

\section{Insulin Receptor/Insulin Receptor Substrate}

The first critical node in the insulin signaling is represented by the interaction between IR and IRS, which share a common mechanism of activation based on tyrosine phosphorylation. In addition to decreased levels of both IR (69) and IRS, protein tyrosine phosphatases (PTPases) are able to dephosphorylate tyrosine residues on the IR $\beta$ subunit and IRS docking molecules, resulting in a dampening of the insulin signal transduction. Therefore, an abnormal overexpression of the PTPases contributes to the insulin resistance in diabetic states in both rodents and humans $(70,71)$. Several PTPases are currently attractive therapeutic targets for obesity and T2D, including PTP1B (72, 73). Indeed, PTP1B is widely expressed and detectable in the insulin-responsive tissues. In this respect, in high-fat diet (HFD) fed mice or hepatocyte models with insulin resistance, the expression of miR-122 is downregulated as a consequence of the
HNF $4 \alpha$ phosphorylation by c-Jun N-terminal kinase 1 (JNK1). This event leads to hepatic insulin resistance through the PTP1B induction and may be overcome by the chemical inhibition of JNK and, subsequently, the rescue of the miR-122/PTP1B levels (74). Moreover, the increase in $\mathrm{miR}-206$ expression is responsible for the downregulation of PTP1B with an improvement of the insulin signaling, thus protecting glomerular podocytes against fructose-induced injury and the consequent proteinuria (75).

In addition to being adaptor proteins that act as negative regulators of cytokine and growth factor signaling, the proteins of the suppressor of cytokine signaling (SOCS), in particular SOCS1 and SOCS3, negatively regulate the insulin signaling, linking the cytokine signaling to insulin resistance (76). The SOCS proteins are of particular importance because they are upregulated in states of insulin resistance, such as obesity, and contribute to the insulin resistance through the inhibition of the tyrosine phosphorylation of IRS $(77,78)$. Found to be significantly downregulated in diabetic patients and mouse models, the miR-185 levels are directly correlated with blood glucose concentration and inversely correlated with the SOCS3 levels in diabetes patients. Therefore, the restoration of miR-185 expression may serve as a potentially promising and efficient therapeutic approach for diabetes (79). The levels of miR-19a-3p are also significantly 
TABLE 1 | MicroRNAs (miRNAs) involved in insulin signaling.

\begin{tabular}{|c|c|c|c|}
\hline Target & miRNA & Cell type/tissue & Reference \\
\hline \multirow[t]{7}{*}{ Insulin receptor } & $m i R-15 b$ & Hepatocytes & (39) \\
\hline & miR-195 & HepG2 & $(40)$ \\
\hline & miR-128a & Skeletal muscle, breast & $(41,42)$ \\
\hline & $\mathrm{miR}-144$ & Blood & $(43)$ \\
\hline & miR-135 & $\mathrm{C} 2 \mathrm{C} 12$ & (44) \\
\hline & Let-7 & $\mathrm{C} 2 \mathrm{C} 12$ & $(45)$ \\
\hline & miR-96 & Hepatocytes & $(46)$ \\
\hline \multirow[t]{2}{*}{ Caveolin-1 } & miR-103/107 & $\begin{array}{l}\text { SGC7901, liver, adipose } \\
\text { tissue }\end{array}$ & $(47,48)$ \\
\hline & $\operatorname{miR}-124$ & N2A/APP695swe & (49) \\
\hline \multirow{8}{*}{$\begin{array}{l}\text { Insulin receptor } \\
\text { substrate } 1 \text { (IRS-1) }\end{array}$} & miR-128a & Skeletal Muscle & $(41)$ \\
\hline & miR-144 & Blood & (43) \\
\hline & Let-7, lin-28 & $\mathrm{C} 2 \mathrm{C} 12$ & (45) \\
\hline & miR-126 & Endothelial cells & (50) \\
\hline & miR-23a & NSCLC & (51) \\
\hline & miR-29 & Myocytes, Skeletal muscle & $(52,53)$ \\
\hline & $\mathrm{miR}-145$ & HepG2 & $(54,55)$ \\
\hline & miR-96 & Hepatocytes & $(47)$ \\
\hline \multirow[t]{3}{*}{ IRS-2 } & miR-135a & Skeletal muscle & $(56)$ \\
\hline & $\mathrm{miR}-126$ & $\beta$-cells & $(57)$ \\
\hline & miR-33a/b & Hepatocytes & (58) \\
\hline \multirow[t]{2}{*}{ PDK1 } & miR-375 & $\beta$-cells & (59) \\
\hline & miR-210 & Endothelial cells & $(60)$ \\
\hline Phosphatidylinositol & miR-128a & Skeletal muscle & $(41)$ \\
\hline \multirow[t]{6}{*}{ 3-kinase } & Let-7 & HepG2 & (45) \\
\hline & miR-126 & Endothelial cells & $(57)$ \\
\hline & miR-503 & NSCLC & (61) \\
\hline & miR-29 & Skeletal muscle & (53) \\
\hline & miR-320 & Adipocytes & (62) \\
\hline & miR-378 & Hepatocytes & (63) \\
\hline \multirow[t]{8}{*}{ AKT } & $\mathrm{miR}-128 \mathrm{a} / \mathrm{b}$ & Skeletal muscle & $(41)$ \\
\hline & $\mathrm{miR}-145$ & HepG2 & (55) \\
\hline & miR-126 & $\beta$-cells & $(57)$ \\
\hline & $\mathrm{miR}-143$ & Liver & (64) \\
\hline & miR-1 & $\mathrm{H} 9 \mathrm{C} 2$ & (65) \\
\hline & miR-423 & Hepatocytes & (66) \\
\hline & miR-29 & Adipocytes & (67) \\
\hline & miR-26b & Adipocytes & (68) \\
\hline
\end{tabular}

decreased in diabetic patients and inversely correlated with the SOCS3 levels, suggesting that the downregulation of miR-19a-3p may contribute to the dysfunction of pancreatic $\beta$ cells through SOCS3. Hence, the miR-19a-3p/SOCS3 axis may also become a potential therapeutic target for diabetes (80). Additionally, miR483 affects the insulin transcription and secretion by targeting SOCS3 in pancreatic $\beta$ cells and an imbalance of miR-483 and SOCS3 may play a crucial role in the pathogenesis of T2D (81). Furthermore, the accumulation of the pro-inflammatory M1 macrophages, which occurs in the adipose tissue, is a central event leading to the metabolic complications related to obesity. The M1 macrophage polarization is due to a significant decrease in the protein levels of SOCS1, a proven target of miR-155, followed by the activation of STAT1 and suppression of STAT6. As miR-155 has been observed to be upregulated in both adipocyte-derived micro-vesicles from obese mice and in macrophages treated with those micro-vesicles, it may mediate the obesity-induced imbalance in the M1-to-M2 macrophage ratio in adipose tissue, contributing to the chronic inflammation state and local insulin resistance (82). Finally, the chronic Helicobacter pylori infection is associated with an increased risk of developing T2D, as it induces hepatic insulin resistance by the c-Jun/miR-203/SOCS3 axis (83).

The serine-threonine phosphorylation of IR and IRS docking proteins is a major mechanism for the negative modulation of the insulin signaling. Indeed, the serine phosphorylation diminishes the IR tyrosine kinase activity and decreases the IR-IRS coupling. There are also consensus sequences in IRS that make it susceptible to a wide variety of serine-threonine kinases, including protein kinase C (PKC), extracellular signal-regulated kinase (ERK), mammalian target for rapamycin (mTOR)/Ribosomal protein S6 kinase beta 1 (S6K1), JNK, and inhibitor of $\kappa B$ kinase beta $(\mathrm{IKK} \beta)$ (84). The ERK and S6K1 are activated by insulin, indicating that the serine phosphorylation of IRS represents a negative feedback mechanism for the insulin signaling pathway, and thus these kinases cause a desensitization to the insulin action under conditions of nutrient excess, inflammation, and cell stress responses. JNK and IKK $\beta$ are activated by inflammatory stimuli, such as tumor necrosis factor alpha (TNF- $\alpha$ ), contributing to insulin resistance in obesity, while conventional and novel PKC isoforms are activated via their recruitment to the plasma membrane by diacylglycerol, accumulated into the cells as a consequence of the increased availability of free fatty acids. miR-15 and miR-16 belong to a common precursor family and are highly conserved. The deletion or downregulation of these two miRNAs has been shown to accelerate cell division by modulating the expression of genes involved in the control of the cell cycle. An in-depth study performed in MDA-MB-231 breast cancer cells has demonstrated that both miR-15 and miR-16 target Ribosomal protein S6 kinase beta 1, control cell proliferation, and cause apoptosis (85). In insulin-resistant conditions, a posttranscriptional regulation of Ribosomal protein S6 kinase beta 1 may be undertaken by miR-15 and miR-16 or by other miRNAs yet to be identified. Furthermore, both miR-199a and miR-199b negatively regulate IKK $\beta$ by binding its $3^{\prime}$-UTR, a fact that is supported by the following studies. Cancer progression is an abnormal form of tissue repair (86), characterized by chronic inflammation in which IKK $\beta$ has a critical role. The differential expression of IKK $\beta$ in epithelial cells isolated from patients with ovarian cancer is inversely correlated with the levels of miR-199a (87). In addition, the inflammatory response plays an important part in the progression of spinal cord injury and the downregulation of miR-199b promotes this process through the IKK $\beta-N F \kappa B$ pathway and microglial cell activation (88). Additionally, miR377 and let-7a directly interact with ERK2 and alter its expression, significantly reducing the basal trophoblast proliferation in placenta (89). Moreover, it has been demonstrated that miR-216b exerts its tumor suppressor function through the inhibition of the Kirsten rat sarcoma viral oncogene homolog (KRAS)-ERK pathway. Indeed, the miR-216b levels inversely correlate with the protein levels of KRAS during nasopharyngeal tumorigenesis and a decrease in its expression is related to the advanced clinical stage and lymph node metastasis via the upregulation of KRAS (90). The latter has also been identified as a target of miR-134 in renal cell carcinoma. Thus, miR-134 may act as a tumor suppressor in cell proliferation and epithelial-mesenchymal transition through 


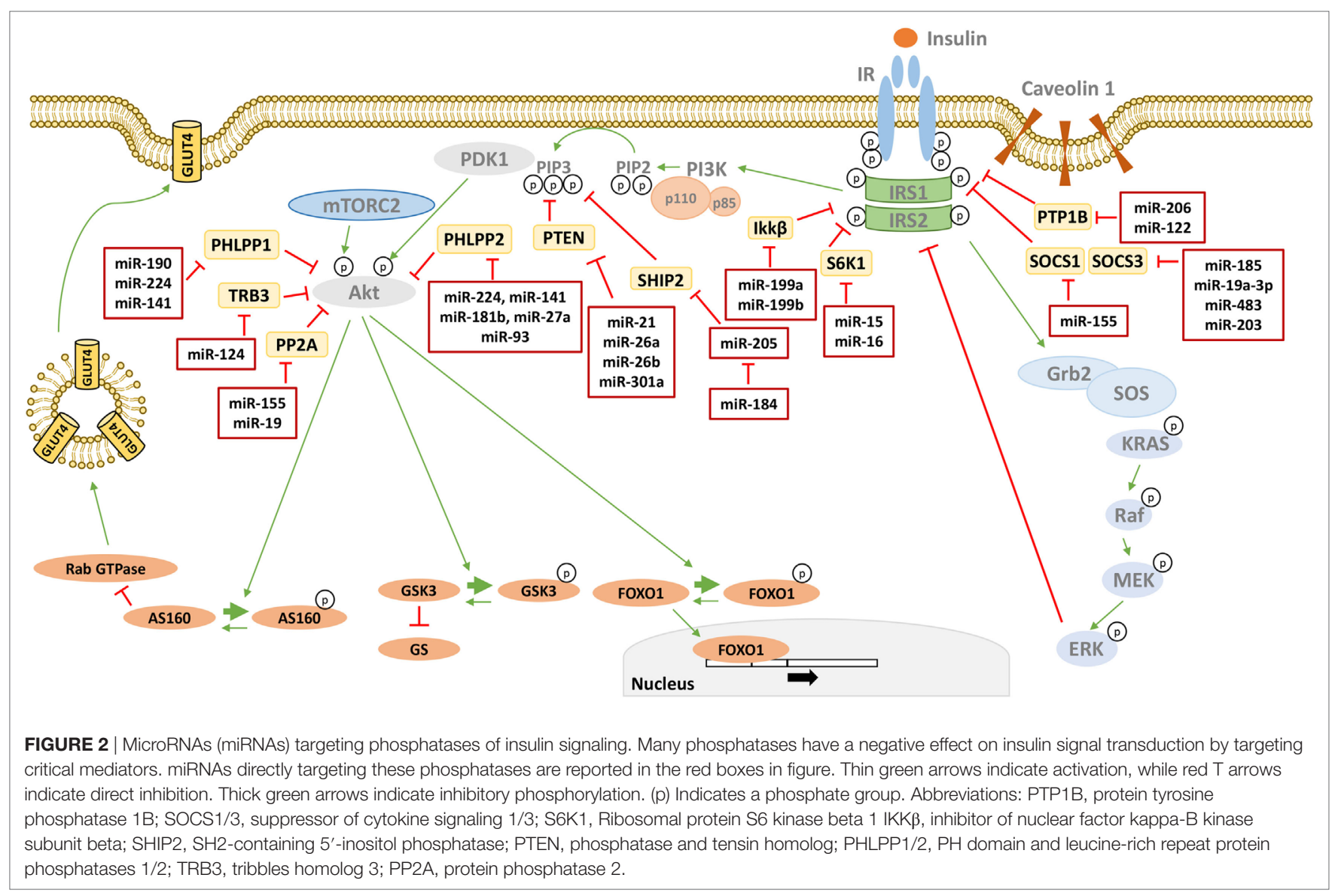

the KRAS/ERK pathway (91). In HepG2 and MHCC97L cancer cells, miR-30a overexpression completely blocks the activation of the KRAS/ERK pathway by directly binding the $3^{\prime}$-UTR of KRAS. Overall, these findings indicate that miR-30a may be involved in the cell growth, apoptosis, and metastasis of hepatocellular carcinoma cells (92). Recently, we have demonstrated that miR-190a downregulation plays a role in the methylglyoxal (MGO)-induced insulin resistance in endothelial cells by increasing the KRAS protein levels. This effect attributed to miR-190a may explain the ERK1/2 hyper-activation and IRS-1 phosphorylation on Ser-616, which we had previously observed in the presence of MGO both in vitro and in vivo (93). Thus, our study highlights miR-190a as a new candidate for the identification of strategies aimed at ameliorating the vascular function in diabetes (94).

\section{Phosphatidylinositol 3-Kinase}

The increased production of phosphatidylinositol $(3,4,5)$-trisphosphate [PtdIns $(3,4,5)$ P3], abbreviated PIP3, the lipid second messenger molecule generated through the phosphorylation of phosphatidylinositol (4,5)-bisphosphate (PIP2) by PI3K, is a decisive event in the insulin signaling related to metabolism (95). Indeed, its binding to proteins with a $\mathrm{PH}$ domain, such as the phosphoinositide-dependent kinase 1 (PDK1), is responsible for the activation of the serine/threonine kinase AKT/PKB and atypical PKCs ( $\alpha$ PKCs). Along with the AKT/PKB activation, $\alpha \mathrm{PKC}$ represent important downstream effectors of PI3K in mediating the metabolic effects of insulin, as they are able to affect the translocation of glucose transporter 4 (GLUT4) and the insulin-induced glucose uptake in the adipocytes and muscles. A decreased activation of $\alpha \mathrm{PKCs}$ has been reported in the muscles of T2D humans and rodents, whereas the AKT/PKB activation may result to be unchanged (96).

In addition to the inhibition due to the regulatory subunit of PI3K (p85), PIP3 produced by this enzyme can be hydrolyzed by phospholipid phosphatases, such as phosphatase and tensin homolog (PTEN) deleted on chromosome 10 and SH2-containing 5 '-inositol phosphatase-2 (SHIP2), which dephosphorylate and inactivate PIP3 on the $3^{\prime}$ - or $5^{\prime}$-position of the inositol ring, respectively. Therefore, PTEN and SHIP2 can exert negative regulatory influences on the insulin signaling, causing PDK1 to cease its activity (97). In hepatocytes, unsaturated fatty acids upregulate the expression of miR-21 and, subsequently, inhibit the tumor suppressor PTEN, since its deletion in the liver leads to insulin resistance, steatosis, inflammation, and cancer. Consistent with these data, the miR-21 expression has been found to be increased in the liver of HFD rats and in obese patients, together with a diminished expression of PTEN and steatosis (98). In addition, miR-21 levels are significantly downregulated in insulin-resistant adipocytes. Considering that PTEN is a well-known target of miR-21, Ling et al. (99) have overexpressed miR-21 in 3T3-L1 adipocytes with insulin resistance induced by high glucose and high insulin to demonstrate that miR-21 may contribute to insulin 
resistance or diabetes. In more detail, in the presence of high levels of miR-21, a relevant increase in the insulin-induced phosphorylation of AKT (Ser-473), the translocation of GLUT4 to the plasma membrane and the insulin-induced glucose uptake have been observed in concomitance with the decrease in the protein levels of PTEN, suggesting this miRNA as a new therapeutic target for metabolic diseases, such as T2D and obesity (99). Furthermore, the decreased miR-26b expression observed in visceral adipose tissue of obese rodent models and human patients may also be involved in obesity-related insulin resistance by interrupting the PTEN/PI3K/AKT pathway. Indeed, miR-26b modulates the insulin-stimulated AKT activation via the inhibition of its target gene PTEN, promoting the GLUT4 translocation to the plasma membrane and insulin-induced glucose uptake in human mature adipocytes. Moreover, the expression of miR-26a is dramatically downregulated in the serum and islets of both HFD and $\mathrm{db} / \mathrm{db}$ mouse models, while its overexpression protects against HFDinduced diabetes and maintains prolonged normal-glycemic time in HFD mice through an improvement of the pancreatic $\beta$ cell function (100). Finally, IL-6 has been implicated in the pathogenesis of insulin resistance. In vivo and in vitro treatments with IL-6 cause the downregulation of miR-301a in the liver, accompanied by an impairment of the AKT/glycogen synthase kinase (GSK) pathway and glycogenesis. The contribution of miR-301a to the IL-6-induced insulin resistance has been demonstrated to be due to a direct effect on the PTEN expression (101).

The lipid phosphatase SHIP2 is a target of miR-205 in epithelial cells. In addition, the corneal epithelial-specific miR-184 can interfere with the ability of miR-205 to suppress the SHIP2 levels, giving an example of a miRNA that negatively regulates another to maintain the levels of a target protein. Interfering with the miR-205 function, miR-184 leads to a dampening of the AKT activity via the SHIP2 induction. This is associated with a marked increase in the keratinocyte apoptosis and cell death (102). As aggressive squamous cell carcinoma cells exhibit elevated levels of miR-205, the blockage of the miR-205 activity with its specific antagomiR- or via the ectopic expression of miR184 may be novel therapeutic approaches for its treatment (103).

\section{AKT/PKB}

The serine/threonine-specific protein kinase AKT/PKB mediates most of the metabolic actions of insulin through the phosphorylation of several substrates, including other kinases, signaling proteins, and transcription factors. The $\mathrm{AKT} / \mathrm{PKB}$ activity is regulated by several inhibitory molecular mechanisms, including tyrosine phosphatases and adaptor proteins.

Protein phosphatase $2 \mathrm{~A}$ ( $\mathrm{PP} 2 \mathrm{~A}$ ), which accounts for $\sim 80 \%$ of the serine/threonine phosphatase activity in the cells, regulates the activities of many protein kinases involved in the insulin action, including AKT/PKB. Several studies indicate that PP2A is hyper-activated in diabetic states (104). In many cancers, the loss of the PP2A activity has been associated with tumorigenesis and drug resistance, due to the failure of turning off survival signals, such as those involving $\mathrm{AKT} / \mathrm{PKB}$ (105). In addition, recent studies have demonstrated that a number of clinically significant miRNAs, including miR-19 (106) and miR-155 (107) may have PP2A as a target.
Other serine/threonine phosphatases have been implicated in the insulin actions. Protein phosphatases $2 \mathrm{~B}$, also known as calcineurin, has been shown to dephosphorylate AKT/PKB. In addition, two novel members of the PP2C family involved in regulation of the insulin signaling are the $\mathrm{PH}$ domain leucinerich repeat protein phosphatases 1 and 2 (PHLPP-1 and PHLPP2), which dephosphorylate both AKT/PKB and PKCs (108). The overexpression of PHLPP1 in cells impairs AKT/PKB and GSK3 activity, resulting in a decrease of the glycogen synthesis and glucose transport (109). Elevated levels of PHLPP1 have been found in the adipose tissue and skeletal muscle of obese and/or diabetic patients and correlate with decreased AKT2 phosphorylation levels $(109,110)$. Regarding the regulation of PHLPP1 expression by miRNAs, published studies have revealed that miR-190 is responsible for the downregulation of PHLPP1, contributing to the $\mathrm{AKT} / \mathrm{PKB}$ activation and carcinogenesis in human bronchial epithelial cells $(111,112)$. Moreover, several other miRNAs affect the PHLPP1 levels in cancer cells while there is no information available on a potential regulation of PHLPP1 at the posttranscriptional level in insulin-resistant conditions. On the contrary, miRNA-181b is able to improve the glucose homeostasis and insulin sensitivity by modulating the PHLPP2 levels in the endothelial cells and, thus, affecting the endothelial function in the white adipose tissue (113). miRNA-181 has been demonstrated to target PHLPP2 in additional conditions, such as in fibrous overgrowths induced by cutaneous injury, called keloid (114) and in luminal breast cancer cells (115). Among the other miRNA identified as regulators of PHLPP2, it is worth mentioning miRNA-27a in gastric cancer cells (116) and miR93 in glioma cell lines and clinical glioma tissues (117). Indeed, the former is highly expressed in the omentum of the obese patients (118) and represses adipocyte differentiation (119), while the latter is overexpressed in adipose tissue of polycystic ovary syndrome patients and women with insulin resistance and regulates the GLUT4 levels (120). Hence, in these conditions with altered miRNA-27a and miR-93, PHLPP2 expression may also be affected. However, this hypothesis remains to be demonstrated. Finally, cases of miRNAs able to modulate both PHLPP1 and PHLPP2 have been reported in the literature, including miR-224 in esophageal squamous cell carcinoma (121) and in colorectal cancer (122), and miR-141 in non-small cell lung cancer (123).

Tribbles homolog 3 (Trb3) is a member of the family of pseudo-kinases and is thought to function as an adaptor protein. Indeed, binding to the un-phosphorylated $\mathrm{AKT} / \mathrm{PKB}$ and blocking its phosphorylation and activation in vivo, it is another brake on the insulin signaling. The Trb3 expression is induced in the liver (124) as well as in the sheletal muscle (125), in fasting and diabetic conditions. In non-alcoholic fatty liver disease and related metabolic diseases, an increase in hepatic triglyceride contents usually occurs and it may be promoted by miR-124 through its confirmed target, TRB3. Indeed, this miRNA is upregulated in the liver of $\mathrm{C} 57 \mathrm{BL} / 6$ mice fed a short-term HFD, which leads to an increase in the accumulation of triglycerides and in the expression of lipogenic genes in the liver, together with an enhancement in the $\mathrm{AKT} / \mathrm{PKB}$ activity (126). 


\section{THE ROLE OF miRNAs IN THE CELLULAR DESTINY OF GLUCOSE}

Insulin resistance is a common feature in patients with T2D and it precedes the development of hyperglycemia. Nevertheless, over the last few decades, despite extensive efforts aimed at gaining a better understanding of the insulin signaling, researchers have been unable to determine many causes of the disease. Therefore, to identify other factors with additive, synergistic or antagonistic effects on the glucose homeostasis, it is important to carefully consider also the cellular metabolic destiny of glucose. Much previous work has been focused on the activity of rate-limiting enzymes in metabolic pathways, regulated by either substrate/ metabolite availability or gene expression (127-129). However, a single enzyme strategy has often been proved to be ineffective because a coordinated dysregulation of several pathways or several components of a single main pathway may occur, due to alterations in the expression of transcription factors and co-factors. In addition, the regulation at the posttranscriptional level by miRNAs with possible simultaneous alterations in multiple steps may also have pathophysiological implications and, thus, it is imperative to reveal the mechanisms based on the miRNA action. Indeed, only a few studies have been published demonstrating a direct regulation of metabolic enzymes due to miRNAs (Figure 3) or an indirect one through the modulation of transcription factors by miRNAs. Therefore, progress in the identification of the miRNAs involved in the pathways related to the glucose metabolism is essential and it may suggest new targets to use for therapy.

\section{The Glucose Uptake}

Previous studies have indicated that glucose transport is a rate-limiting step for the glucose metabolism. Indeed, due to its hydrophilic nature, glucose cannot penetrate the lipid bilayer and therefore specific transporter proteins, known as GLUTs, are required to facilitate the diffusion into cells down its concentration gradient. GLUT1 is a widely expressed isoform that provides glucose transport under basal conditions for many cell types. Moreover, the exposure of cells to several stresses results in an acute increase in the entry of glucose into the cells by GLUT1 (130), considered as an adaptive response to meet specific energy demands. The activity of GLUT1 is modulated through changes in its gene expression also due to miRNAs, such as miR-143 in the placenta of obese women with gestational diabetes mellitus (131) and many others altered in cancer $(132,133)$. GLUT4 is the major mediator of extracellular glucose clearance, playing a key role in the regulation of glycemic homeostasis. Indeed, in the skeletal muscle and adipose tissue, GLUT4 mediates the insulin-stimulated glucose uptake by a mechanism involving the translocation between cellular compartments and the increased glucose entry rate is due to a greater amount of GLUT4 at the cell membrane under insulin stimulation (134). Due to a reduction of the GLUT4 expression and/or translocation, the decreased insulin-stimulated glucose uptake is a common feature and contributes to the impairment in the glycemic control in the adipose tissue and skeletal muscle of pre-diabetic and diabetic

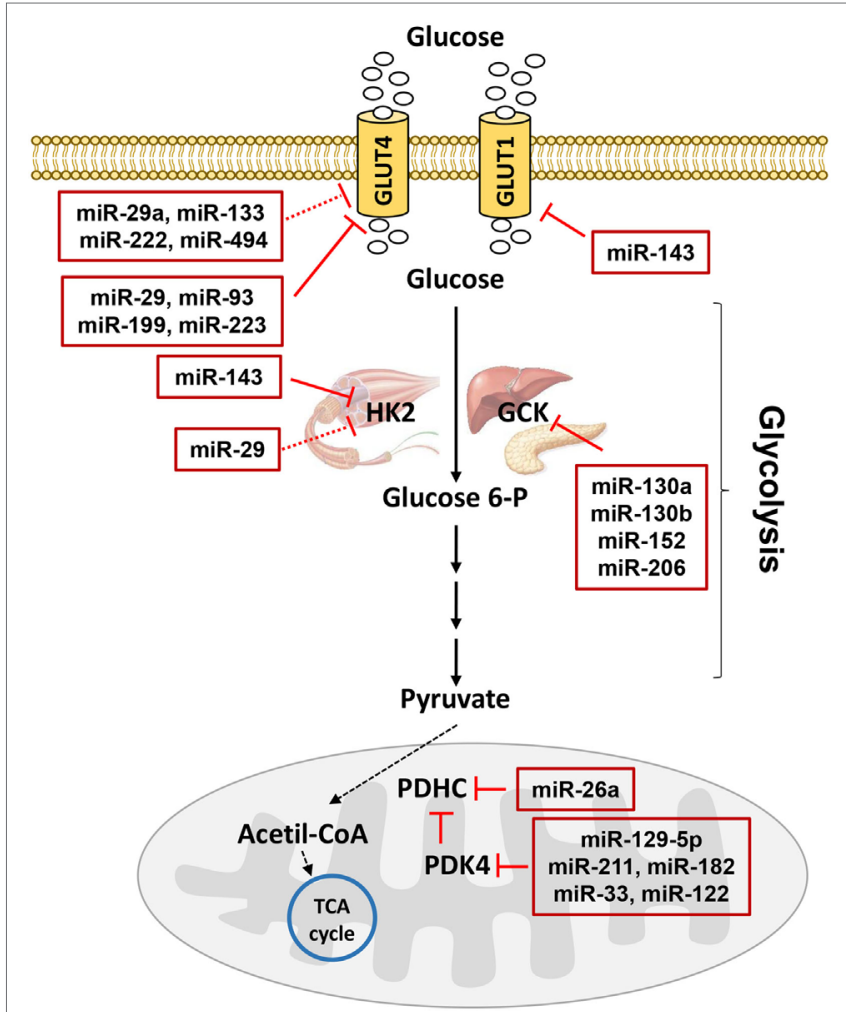

FIGURE 3 | MicroRNAs (miRNAs) involved in glucose metabolism. Glucose transporters (GLUTs) mediate glucose entrance into the cells where it is transformed in pyruvate by glycolysis. Hexokinase 2 (HK2) catalyzes the conversion of glucose to glucose 6-phosphate in muscle, while glucokinase catalyzes the same reaction in liver and pancreas. In mitochondria, pyruvate dehydrogenase complex (PDHC) transforms pyruvate in acetil-coenzyme A (COA) allowing the entrance to the tricarboxylic acid (TCA) cycle. PDHC activity is controlled by pyruvate dehydrogenase kinase 4 (PDK4). miRNAs targeting GLUTs and enzymes catalyzing glucose metabolism are reported in the red boxes in figure. Red T arrows indicate direct inhibition, while red $T$ dotted arrows indicate indirect inhibition.

subjects (135-138). Several miRNAs, many of which not yet identified, are involved in the expression of GLUT4 or proteins responsible for the GLUT4 translocation. As the levels of these miRNAs may be altered in metabolic diseases, their contribution to insulin resistance and diabetes has been suggested. In conditions related to insulin resistance and $\mathrm{T} 2 \mathrm{D}$, the role of miRNAs on the GLUT4 expression has been investigated only in a few studies performed not only in the skeletal muscle but also in adipose and cardiac tissues or cells. miR-29 (53), miR-93 (120), miR-199a (139), and miR-223 $(140,141)$ have a direct effect on the GLUT4 mRNA levels. Moreover, other miRNAs have an effect on regulators of the GLUT4 expression. For instance, in addition to its action at the 3'UTR of GLUT4, miR-29a targets peroxisome proliferator-activated receptor delta, which in turn reduces a transcriptional coactivator essential for GLUT4, namely peroxisome proliferator-activated receptor gamma coactivator 1 alpha (142). Additionally, miR-133 targets Krueppel-like factor 15 in the cardiomyocytes (143), while miR-222 targets estrogen receptor alpha in the omental adipose tissues from gestational diabetes 
mellitus subjects (144). Furthermore, only a few miRNAs have been linked to the expression of proteins involved in the GLUT4 translocation machinery in the muscle, impacting on the glucose uptake. One such miRNA is miR-494, which regulates syntaxinbinding protein 5 in C2C12 cells (145). All these miRNAs related to GLUT4 represent promising targets for preventive and/or therapeutic approaches aimed at improving glycemic control and, therefore, deserve future investigation.

\section{The Glycolytic Metabolism}

Glycolysis is the pathway through which glucose is broken down into pyruvate, providing the substrate for energy production as well as for energy storage through glycogenesis and lipogenesis. Immediately following its transport into cells, hexokinases phosphorylate the glucose to trap it within the cell. Hexokinase 2 (HK2) expression and activity are reduced in the skeletal muscle of subjects with T2D (146). As insulin induces the HK2 expression in the skeletal muscle via PI3K and the p85 $\alpha$ regulatory subunit of PI3K is a validated target of miR-29 (147), this miRNA has been suggested being an indirect cause of the reduction in the HK2 mRNA levels with a consequent loss of its activity observed in skeletal muscle cells overexpressing miR-29 (53). Conversely, HK2 is highly expressed in tumors $(148,149)$ and its regulation by miRNAs has been demonstrated in several studies. Since miR-143 has been found to be downregulated in cancer cells and since it is able to directly target HK2 (150-152), its upregulation observed in diabetic conditions $(64,131)$ may explain the reduced expression of HK2. However, this hypothesis remains to be demonstrated.

The glucokinase (GCK, the predominant hexokinase isoenzyme in the hepatic and pancreatic $\beta$ cells) was one of the first candidate genes to be identified as a human "diabetogene," since its heterozygote inactivating mutation was reported to be a subtype of the maturity-onset diabetes of the young, causing reduced insulin secretion and hyperglycemia. In the liver, the status of GCK as a prominent player in the regulation of glucose metabolism supports the important role of the glycolytic process in the regulation of the hepatic glucose production and, consequently, in the maintenance of glucose homeostasis (153). The transcriptional regulation of GCK has been extensively studied (154) and a dramatic induction by insulin has been demonstrated, whereas miRNAs involved in its posttranscriptional regulation are still "in the black box." Recently, GCK protein levels have been found to be downregulated in the Goto-Kakizaki rat islets, in accordance with the elevated expression of miR-130a, miR-130b, and miR152 (155). In addition, a novel mechanism of posttranscriptional regulation of GCK by miR-206 has been revealed (156). As an induction in the expression of GCK promotes hepatic glucose utilization, the development of the GCK activators has generated exciting results at the pre-clinical phase in the diabetic field, but has also revealed some limitations (157). On the other hand, the identification of miRNAs as modulators of the GCK levels may represent an alternative approach and show greater promise from a therapeutic perspective.

In adipocytes, the glucose phosphorylation catalyzed by hexokinase is not a rate-limiting step, while 6-phosphofructo2-kinase/fructose 2,6-bisphosphatase-3 (PFK-2/FBPase-2) is more significant as it serves as a coordinator that links adipocyte glycolysis, glycolysis-driven lipogenesis, and the inflammatory response. The latter enzyme is downregulated by miR-26b in osteosarcoma cells (158). In addition, the miRNA-26 family is required for human adipogenesis (159) and miR-26b modulates insulin sensitivity in adipocytes by interrupting the PTEN/PI3K/ AKT pathway (68). Thus, this miRNA may also play a yet undiscovered role in targeting PFK-2/FBPase- 2 in adipocytes.

\section{The Mitochondrial Oxidative Metabolism}

Pyruvate is a key intermediate in several metabolic pathways. Made from glucose through glycolysis, pyruvate molecules can be converted back into carbohydrates (such as glucose) via gluconeogenesis or into fatty acids through a reaction with acetyl-coenzyme A (CoA). In addition, pyruvate supplies energy to cells through the tricarboxylic acid (TCA) cycle (also known as the citric acid cycle or the Krebs cycle) in aerobic conditions or, alternatively, ferments to produce lactate in anaerobic conditions. Hence, a stringent control of the destiny of pyruvate is critical for cellular homeostasis and the following enzymes in its metabolism are of great importance:

(a) Mitochondrial pyruvate carrier (MPC), which is located in the mitochondrial inner membrane and carries pyruvate from the intermembrane space into the mitochondrial matrix space. Recently, MPC activity has been shown to be activated by the mitochondrial deacetylase sirtuin-3 (160). As yet, no miRNAs have been identified as regulators of MPC.

(b) Pyruvate carboxylase (PC), which converts pyruvate into oxaloacetate necessary for lipogenesis in the fed state and for hepatic gluconeogenesis in the fasted state. Since PC catalyzes the committed step in gluconeogenesis and the PC protein levels correlate with glycemic levels in subjects with T2D, factors that may affect its expression and/or activity are receiving growing interest within the scientific community, in accordance with the increased standing of $\mathrm{PC}$ as a potential therapeutic target (161). Among these factors, miRNAs may be included. As no research has been undertaken to date, future studies are required to find a possible involvement of miRNAs in the $\mathrm{PC}$ regulation.

(c) Pyruvate dehydrogenase complex (PDHC), which inserts pyruvate into the TCA cycle catalyzing the irreversible decarboxylation of pyruvate into acetyl-CoA. Interconnecting glycolysis and the TCA cycle, PDHC is critical for the control of the glucose metabolism in the fasted-fed cycle. Indeed, PDHC is highly active in the fed state and glucose is oxidized to generate energy or is rerouted to glycogen as an energy storage. By contrast, this enzyme is inactivated in the fasted state, when glucose is in demand and three carbon compounds need to be conserved for the hepatic gluconeogenesis to maintain the whole-body glucose homeostasis. In this condition, lipolysis is activated and fatty acids become the preferred fuel (the glucose-fatty acid cycle) (162). Hence, considering the key role it plays in glucose disposal, a close control of the PDHC expression and activity is required. Indeed, an inappropriate suppression of its activity in the 
skeletal muscle promotes the development of hyperglycemia through excessive gluconeogenesis.

Regarding the posttranscriptional regulation of $\mathrm{PDHC}$ expression, miR-26a regulates the glucose metabolism of colorectal cancer cells by directly targeting the E3 binding protein subunit, also known as component X (PDHX) of PDHC, efficiently improving the accumulation of pyruvate and decreasing the production of acetyl-CoA (163). However, in addition to its metabolic role in tumorigenesis targeting PDHX, Fu et al. (164) have demonstrated that miR-26a regulates the insulin signaling and metabolism in the liver. In addition, overweight individuals show a decrease in the miR-26a hepatic expression compared to lean controls and a downregulation has been observed also in two different mouse models of obesity (164). On the other hand, the expression of miR-26a is rapidly induced in response to high glucose in the endothelial cells and it may be an important regulator in the progression of skin wounds of diabetic mice, being able to affect the angiogenic response after injury (165). Questions about a potential role of miR-26a in metabolic diseases through its effect on PDHX and about the existence of other miRNAs able to regulate $\mathrm{PDHC}$ require further investigation.

The control of PDHC activity is achieved through a reversible, inactivating phosphorylation by pyruvate dehydrogenase kinase (PDK) (166). Of all the known isozymes, pyruvate dehydrogenase kinase 2 and pyruvate dehydrogenase kinase 4 are the most widely distributed and are highly expressed in the heart, liver, and kidneys in humans and rodents. PDK4 is also abundant in the skeletal muscle, which shows high glucose utilization and fatty acid oxidation rates. Not only can the PDK4 activity be regulated by metabolites but also the PDK4 expression is influenced by many factors that have been extensively studied (167). At the transcription level, forkhead box protein O1 (FOXO1) has been proposed as one of the main regulators of the PDK4 expression, mediating the insulin-dependent repression as a consequence of the AKT/PKB-dependent phosphorylation and nuclear exclusion. Hence, under insulin stimulation and PDK4 repression, the skeletal muscle is able to switch from lipid oxidation to elevated glucose uptake, oxidation, and storage since PDHC is in the active state. During short-term energy deprivation, the dephosphorylated FOXO1 remains in the nucleus and binds the PDK4 promoter, inducing its expression. Fatty acid oxidation is then preferred to glucose oxidation, as a consequence of the PDHC inhibition (168).

In obese and diabetic subjects, insulin resistance is mostly characterized by a reduction in both the stimulation of the glucose metabolism and the suppression of lipid utilization in the skeletal muscle. Thus, the capacity to switch between fuels is defective, a condition known as "metabolic inflexibility" (a failure to adapt the metabolism to the fasted-to-fed state transition) (169). Since the incapacity of insulin to downregulate PDK4 has been demonstrated in obese and diabetic subjects (170), the consequent increase in the PDK4 levels associated with an inappropriate suppression of the PDHC activity may promote the development of metabolic diseases (171).

Furthermore, the environment may also have an effect on the PDK4 expression and glucose metabolism. Indeed, changes in the PDK4 mRNA expression in the skeletal muscle have been shown to correlate with the improvement in insulin sensitivity in obese patients after bariatric surgery, demonstrating the link between PDK4 expression and fat mass (172). In this regard, in the skeletal muscle, an inverse correlation has been demonstrated between the PDK4 expression and DNA methylation, involving specifically cytosines in the +160 and +446 regions of the PDK4 promoter. Obesity is associated with an altered methylation and expression of PDK4, while weight loss by gastric bypass surgery is able to normalize the levels of both PDK4 methylation and PDK4 expression to those observed in normal-weight, healthy controls (173). The methylation status and expression levels of PDK4 are also altered in T2D patients, but exercise is able to revert these effects (174). Therefore, changes in the environment, such as weight loss and exercise, have significant beneficial outcomes also by modulating the PDK4 expression.

As an increase in the PDHC activity by a PDK4 inhibitor promotes glucose oxidation and lowers the blood glucose concentration, small molecule inhibitors for PDKs are promising therapeutic agents for patients with metabolic diseases. Actually, therapeutic interventions have already been tested to reduce the PDK4 expression and promote glucose disposal in animal models of diabetes. Preliminary studies have shown encouraging results with the oral administration of dichloroacetate (175), but this compound has a low potency and specificity for PDK4 and is toxic $(176,177)$. The modulation of the PDK4 expression by miRNAs may be an alternative therapeutic approach. However, at present, there are only a few very recent studies regarding the posttranscriptional regulation of PDK4 by miRNAs. Most of these have been performed using cancer cells, in the wake of the mounting interest in the reprogramming of the glucose metabolism in cancer. In relation to miR-129-5p, it targets PDK4 and inhibits glycolysis, thus retarding tumor growth and impairing carcinogenesis in the liver and colonization in the lung (178). The tumor suppressor miR-211 is significantly reduced or absent in non-pigmented melanoma cells and is lost during human melanoma progression. This event represents an important metabolic switch through the regulation of PDK4 (35). Moreover, miR-33 and miR-122, which are commonly altered in metabolic disorders, have been demonstrated to directly target PDK4 in the macrophages to promote cholesterol efflux and reduce atherosclerosis (179) and in the CD133 (+) hepatocellular cancer stem cells (180), respectively. Furthermore, miR-182 is able to modulate glucose utilization by targeting PDK4 both in the muscle of short-term HFD mice (181) and lung cancer cells (35), providing confidence of its effectiveness in other similar examples.

\section{CONCLUSION}

MicroRNAs have emerged as important regulators of multiple aspects of the metabolic homeostasis and changes in their expression may prove to be crucial in determining the metabolic status, normal or pathological. In general, miRNAs are able to regulate the cellular metabolism in two different ways. Indeed, miRNAs modulate transcription factor or signaling protein expression, which in turn affects the levels and/or the activity of the metabolic enzymes. Alternatively, miRNAs control the production of certain 
metabolites by directly regulating the expression of those genes encoding metabolic enzymes at the posttranscriptional level.

In the last few years, much work has been carried out taking into account the metabolic reprogramming of transformed cells (the Warburg effect), identifying miRNAs able to switch from the TCA cycle to aerobic glycolysis (lactate production) by targeting metabolic transporters (like GLUTs) or enzymes (HK2 and PDKs) and by constitutively activating, among others, the PI3K/AKT/ mTOR pathway. Paradoxically, the role of miRNAs in metabolic diseases still remains not well explained and further investigation is required, supported by the increasing evidence of the association between miRNAs and the cancer metabolic reprogramming (182). In addition, most researchers seem to focus on defects in the insulin signaling rather than on other aspects of the metabolism, but it would be appropriate to consider the metabolism in a broader perspective, since miRNAs are involved in several, if not all, metabolic processes.

In relation to $\mathrm{T} 2 \mathrm{D}$, the discovery of an association between miRNAs and metabolism may attract significant interest not only from a scientific but also from a clinical point of view, providing

\section{REFERENCES}

1. DeFronzo RA. Pathogenesis of type 2 diabetes mellitus. Med Clin North Am (2004) 88(4):787-835, ix. doi:10.1016/j.mcna.2004.04.013

2. Boucher J, Kleinridders A, Kahn CR. Insulin receptor signaling in normal and insulin-resistant states. Cold Spring Harb Perspect Biol (2014) 6:1. doi:10.1101/ cshperspect.a009191

3. Pullinger CR, Goldfine ID, Tanyolac S, Movsesyan I, Faynboym M, Durlach V, et al. Evidence that an HMGA1 gene variant associates with type 2 diabetes, body mass index, and high-density lipoprotein cholesterol in a HispanicAmerican population. Metab Syndr Relat Disord (2014) 12(1):25-30. doi:10.1089/met.2013.0086

4. Raciti GA, Longo M, Parrillo L, Ciccarelli M, Mirra P, Ungaro P, et al. Understanding type 2 diabetes: from genetics to epigenetics. Acta Diabetol (2015) 52(5):821-7. doi:10.1007/s00592-015-0741-0

5. Kwak SH, Park KS. Recent progress in genetic and epigenetic research on type 2 diabetes. Exp Mol Med (2016) 48:e220. doi:10.1038/emm.2016.7

6. Banerjee J, Nema V, Dhas Y, Mishra N. Role of microRNAs in type 2 diabetes and associated vascular complications. Biochimie (2017) 139:9-19. doi:10.1016/j.biochi.2017.05.007

7. Bartel DP. MicroRNAs: target recognition and regulatory functions. Cell (2009) 136(2):215-33. doi:10.1016/j.cell.2009.01.002

8. Winter J, Jung S, Keller S, Gregory RI, Diederichs S. Many roads to maturity: microRNA biogenesis pathways and their regulation. Nat Cell Biol (2009) 11(3):228-34. doi:10.1038/ncb0309-228

9. Finnegan EF, Pasquinelli AE. MicroRNA biogenesis: regulating the regulators. Crit Rev Biochem Mol Biol (2013) 48(1):51-68. doi:10.3109/10409238. 2012.738643

10. Meijer HA, Smith EM, Bushell M. Regulation of miRNA strand selection: follow the leader? Biochem Soc Trans (2014) 42(4):1135-40. doi:10.1042/BST20140142

11. Ro S, Park C, Young D, Sanders KM, Yan W. Tissue-dependent paired expression of miRNAs. Nucleic Acids Res (2007) 35(17):5944-53. doi:10.1093/ nar/gkm641

12. Guo L, Lu Z. The fate of miRNA* strand through evolutionary analysis: implication for degradation as merely carrier strand or potential regulatory molecule? PLoS One (2010) 5(6):e11387. doi:10.1371/journal.pone.0011387

13. Yang JS, Phillips MD, Betel D, Mu P, Ventura A, Siepel AC, et al. Widespread regulatory activity of vertebrate microRNA* species. RNA (2011) 17(2): 312-26. doi:10.1261/rna.2537911

14. Kang SM, Choi JW, Hong SH, Lee HJ. Up-regulation of microRNA* strands by their target transcripts. Int J Mol Sci (2013) 14(7):13231-40. doi:10.3390/ ijms 140713231 an appealing therapeutic approach, owing to the small size of miRNAs and specificity on their targeting gene, and suggesting them as candidate molecular biomarkers for the diagnosis and/ or prognosis of T2D in the future. Additionally, in combination with inhibitors highly specific for metabolic enzymes, miRNAs may constitute a powerful strategy to win the battle against T2D.

\section{AUTHOR CONTRIBUTIONS}

All authors listed have made a substantial, direct, and intellectual contribution to the work and approved it for publication.

\section{FUNDING}

This study was funded by the European Foundation for the Study of Diabetes (EFSD)/Novo Nordisk (2015-2017), by the Ministero dell'Istruzione, dell'Università e della Ricerca Scientifica (grants PRIN, PON 01_02460 and POR 03PE_00060_8 Campania Bioscience), by a SID-FO.DI.RI-MSD 2014 fellowship (20152016), and by SID-FO.RI.SID and Eli Lilly Italy.

15. Winter J, Diederichs S. Argonaute-3 activates the let-7a passenger strand microRNA. RNA Biol (2013) 10(10):1631-43. doi:10.4161/rna.26424

16. Bang C, Batkai S, Dangwal S, Gupta SK, Foinquinos A, Holzmann A, et al. Cardiac fibroblast-derived microRNA passenger strand-enriched exosomes mediate cardiomyocyte hypertrophy. J Clin Invest (2014) 124(5):2136-46. doi:10.1172/JCI70577

17. Potla R, Singh IS, Atamas SP, Hasday JD. Shifts in temperature within the physiologic range modify strand-specific expression of select human microRNAs. RNA (2015) 21(7):1261-73. doi:10.1261/rna.049122.114

18. Friedman RC, Farh KK, Burge CB, Bartel DP. Most mammalian mRNAs are conserved targets of microRNAs. Genome Res (2009) 19(1):92-105. doi:10.1101/gr.082701.108

19. Akbari Moqadam F, Pieters R, den Boer ML. The hunting of targets: challenge in miRNA research. Leukemia (2013) 27(1):16-23. doi:10.1038/leu.2012.179

20. Martinez-Sanchez A, Murphy CL. MicroRNA target identification-experimental approaches. Biology (Basel) (2013) 2(1):189-205. doi:10.3390/ biology2010189

21. Asli NS, Pitulescu ME, Kessel M. MicroRNAs in organogenesis and disease. Curr Mol Med (2008) 8(8):698-710. doi:10.2174/156652408786733739

22. Vidigal JA, Ventura A. The biological functions of miRNAs: lessons from in vivo studies. Trends Cell Biol (2015) 25(3):137-47. doi:10.1016/j.tcb.2014.11.004

23. Vienberg S, Geiger J, Madsen S, Dalgaard LT. MicroRNAs in metabolism. Acta Physiol (Oxf) (2017) 219(2):346-61. doi:10.1111/apha.12681

24. Arner P, Kulyte A. MicroRNA regulatory networks in human adipose tissue and obesity. Nat Rev Endocrinol (2015) 11(5):276-88. doi:10.1038/nrendo.2015.25

25. Brandao BB, Guerra BA, Mori MA. Shortcuts to a functional adipose tissue: the role of small non-coding RNAs. Redox Biol (2017) 12:82-102. doi:10.1016/ j.redox.2017.01.020

26. Dumortier O, Fabris G, Van Obberghen E. Shaping and preserving beta-cell identity with microRNAs. Diabetes Obes Metab (2016) 18(Suppl 1):51-7. doi:10.1111/dom.12722

27. Martinez-Sanchez A, Rutter GA, Latreille M. miRNAs in beta-cell development, identity, and disease. Front Genet (2016) 7:226. doi:10.3389/fgene.2016.00226

28. Chakraborty C, Doss CG, Bandyopadhyay S, Agoramoorthy G. Influence of miRNA in insulin signaling pathway and insulin resistance: micro-molecules with a major role in type-2 diabetes. Wiley Interdiscip Rev RNA (2014) 5(5):697-712. doi:10.1002/wrna.1240

29. Calderari S, Diawara MR, Garaud A, Gauguier D. Biological roles of microRNAs in the control of insulin secretion and action. Physiol Genomics (2017) 49(1):1-10. doi:10.1152/physiolgenomics.00079.2016

30. Feng J, Xing W, Xie L. Regulatory roles of microRNAs in diabetes. Int J Mol Sci (2016) 17:10. doi:10.3390/ijms17101729 
31. Hashimoto N, Tanaka T. Role of miRNAs in the pathogenesis and susceptibility of diabetes mellitus. J Hum Genet (2017) 62(2):141-50. doi:10.1038/ jhg. 2016.150

32. Becker N, Lockwood CM. Pre-analytical variables in miRNA analysis. Clin Biochem (2013) 46(10-11):861-8. doi:10.1016/j.clinbiochem.2013.02.015

33. Sethupathy $P$. The promise and challenge of therapeutic microRNA silencing in diabetes and metabolic diseases. Curr Diab Rep (2016) 16(6):52. doi:10.1007/s11892-016-0745-3

34. van Rooij E, Kauppinen S. Development of microRNA therapeutics is coming of age. EMBO Mol Med (2014) 6(7):851-64. doi:10.15252/emmm.201100899

35. Adams BD, Parsons C, Walker L, Zhang WC, Slack FJ. Targeting noncoding RNAs in disease. J Clin Invest (2017) 127(3):761-71. doi:10.1172/JCI84424

36. Mirra P, Raciti GA, Nigro C, Fiory F, D’Esposito V, Formisano P, et al. Circulating miRNAs as intercellular messengers, potential biomarkers and therapeutic targets for type 2 diabetes. Epigenomics (2015) 7(4):653-67. doi:10.2217/epi.15.18

37. Raffort J, Hinault C, Dumortier O, Van Obberghen E. Circulating microRNAs and diabetes: potential applications in medical practice. Diabetologia (2015) 58(9):1978-92. doi:10.1007/s00125-015-3680-y

38. Taniguchi CM, Emanuelli B, Kahn CR. Critical nodes in signalling pathways: insights into insulin action. Nat Rev Mol Cell Biol (2006) 7(2):85-96. doi:10.1038/nrm1837

39. Yang WM, Jeong HJ, Park SW, Lee W. Obesity-induced miR-15b is linked causally to the development of insulin resistance through the repression of the insulin receptor in hepatocytes. Mol Nutr Food Res (2015) 59(11):2303-14. doi:10.1002/mnfr.201500107

40. Yang WM, Jeong HJ, Park SY, Lee W. Saturated fatty acid-induced miR-195 impairs insulin signaling and glycogen metabolism in HepG2 cells. FEBS Lett (2014) 588(21):3939-46. doi:10.1016/j.febslet.2014.09.006

41. Motohashi N, Alexander MS, Shimizu-Motohashi Y, Myers JA, Kawahara G, Kunkel LM. Regulation of IRS1/Akt insulin signaling by microRNA-128a during myogenesis. J Cell Sci (2013) 126(Pt 12):2678-91. doi:10.1242/jcs. 119966

42. Xiao M, Lou C, Xiao H, Yang Y, Cai X, Li C, et al. miR-128 regulation of glucose metabolism and cell proliferation in triple-negative breast cancer. Br J Surg (2018) 105(1):75-85. doi:10.1002/bjs.10646

43. Karolina DS, Armugam A, Tavintharan S, Wong MT, Lim SC, Sum CF, et al. MicroRNA 144 impairs insulin signaling by inhibiting the expression of insulin receptor substrate 1 in type 2 diabetes mellitus. PLoS One (2011) 6(8):e22839. doi:10.1371/journal.pone.0022839

44. Honardoost M, Arefian E, Soleimani M, Soudi S, Sarookhani MR. Development of insulin resistance through induction of miRNA-135 in C2C12 cells. Cell J (2016) 18(3):353-61. doi:10.22074/cellj.2016.4563

45. Zhu H, Shyh-Chang N, Segre AV, Shinoda G, Shah SP, Einhorn WS, et al. The Lin28/let-7 axis regulates glucose metabolism. Cell (2011) 147(1):81-94. doi:10.1016/j.cell.2011.08.033

46. Yang WM, Min KH, Lee W. Induction of miR-96 by dietary saturated fatty acids exacerbates hepatic insulin resistance through the suppression of INSR and IRS-1. PLoS One (2016) 11(12):e0169039. doi:10.1371/journal.pone.0169039

47. Zhang Y, Qu X, Li C, Fan Y, Che X, Wang X, et al. miR-103/107 modulates multidrug resistance in human gastric carcinoma by downregulating CAV-1. Tumour Biol (2015) 36(4):2277-85. doi:10.1007/s13277-014-2835-7

48. Trajkovski M, Hausser J, Soutschek J, Bhat B, Akin A, Zavolan M, et al. MicroRNAs 103 and 107 regulate insulin sensitivity. Nature (2011) 474(7353): 649-53. doi:10.1038/nature10112

49. Kang Q, Xiang Y, Li D, Liang J, Zhang X, Zhou F, et al. miR-124-3p attenuates hyperphosphorylation of tau protein-induced apoptosis via caveolin-1PI3K/Akt/GSK3beta pathway in N2a/APP695swe cells. Oncotarget (2017) 8(15):24314-26. doi:10.18632/oncotarget.15149

50. Fang S, Ma X, Guo S, Lu J. MicroRNA-126 Inhibits cell viability and invasion in a diabetic retinopathy model via targeting IRS-1. Oncol Lett (2017) 14(4):4311-8. doi:10.3892/ol.2017.6695

51. Cao M, Li Y, Lu H, Meng Q, Wang L, Cai L, et al. miR-23a-mediated migration/invasion is rescued by its target, IRS-1, in non-small cell lung cancer cells. J Cancer Res Clin Oncol (2014) 140(10):1661-70. doi:10.1007/ s00432-014-1725-0

52. Yang WM, Jeong HJ, Park SY, Lee W. Induction of miR-29a by saturated fatty acids impairs insulin signaling and glucose uptake through translational repression of IRS-1 in myocytes. FEBS Lett (2014) 588(13):21706. doi:10.1016/j.febslet.2014.05.011

53. Massart J, Sjogren RJO, Lundell LS, Mudry JM, Franck N, O’Gorman DJ, et al. Altered miR-29 expression in type 2 diabetes influences glucose and lipid metabolism in skeletal muscle. Diabetes (2017) 66(7):1807-18. doi:10.2337/ db17-0141

54. Wang Y, Hu C, Cheng J, Chen B, Ke Q, Lv Z, et al. MicroRNA-145 suppresses hepatocellular carcinoma by targeting IRS1 and its downstream Akt signaling. Biochem Biophys Res Commun (2014) 446(4):1255-60. doi:10.1016/j. bbrc.2014.03.107

55. Wen F, Yang Y, Jin D, Sun J, Yu X, Yang Z. miRNA-145 is involved in the development of resistin-induced insulin resistance in HepG2 cells. Biochem Biophys Res Commun (2014) 445(2):517-23. doi:10.1016/j.bbrc.2014.02.034

56. Agarwal P, Srivastava R, Srivastava AK, Ali S, Datta M. miR-135a targets IRS2 and regulates insulin signaling and glucose uptake in the diabetic gastrocnemius skeletal muscle. Biochim Biophys Acta (2013) 1832(8):1294-303. doi:10.1016/j.bbadis.2013.03.021

57. Tao H, Wang MM, Zhang M, Zhang SP, Wang CH, Yuan WJ, et al. miR-126 suppresses the glucose-stimulated proliferation via IRS-2 in INS-1 beta cells. PLoS One (2016) 11(2):e0149954. doi:10.1371/journal.pone.0149954

58. Davalos A, Goedeke L, Smibert P, Ramirez CM, Warrier NP, Andreo U, et al. miR-33a/b contribute to the regulation of fatty acid metabolism and insulin signaling. Proc Natl Acad Sci U S A (2011) 108(22):9232-7. doi:10.1073/ pnas. 1102281108

59. El Ouaamari A, Baroukh N, Martens GA, Lebrun P, Pipeleers D, van Obberghen E. miR-375 targets 3'-phosphoinositide-dependent protein kinase- 1 and regulates glucose-induced biological responses in pancreatic beta-cells. Diabetes (2008) 57(10):2708-17. doi:10.2337/db07-1614

60. Li Y, Yang C, Zhang L, Yang P. MicroRNA-210 induces endothelial cell apoptosis by directly targeting PDK1 in the setting of atherosclerosis. Cell Mol Biol Lett (2017) 22:3. doi:10.1186/s11658-017-0033-5

61. Yang Y, Liu L, Zhang Y, Guan H, Wu J, Zhu X, et al. miR-503 targets PI3K p85 and IKK-beta and suppresses progression of non-small cell lung cancer. Int J Cancer (2014) 135(7):1531-42. doi:10.1002/ijc.28799

62. Ling HY, Ou HS, Feng SD, Zhang XY, Tuo QH, Chen LX, et al. Changes in microRNA (miR) profile and effects of miR-320 in insulin-resistant 3T3-L1 adipocytes. Clin Exp Pharmacol Physiol (2009) 36(9):e32-9. doi:10.1111/j.1440-1681.2009.05207.x

63. Liu W, Cao H, Ye C, Chang C, Lu M, Jing Y, et al. Hepatic miR-378 targets P110alpha and controls glucose and lipid homeostasis by modulating hepatic insulin signalling. Nat Commun (2014) 5:5684. doi:10.1038/ncomms6684

64. Jordan SD, Kruger M, Willmes DM, Redemann N, Wunderlich FT, Bronneke HS, et al. Obesity-induced overexpression of miRNA-143 inhibits insulin-stimulated Akt activation and impairs glucose metabolism. Nat Cell Biol (2011) 13(4):434-46. doi:10.1038/ncb2211

65. Chen T, Ding G, Jin Z, Wagner MB, Yuan Z. Insulin ameliorates miR-1induced injury in $\mathrm{H} 9 \mathrm{C} 2$ cells under oxidative stress via Akt activation. Mol Cell Biochem (2012) 369(1-2):167-74. doi:10.1007/s11010-012-1379-7

66. Yang W, Wang J, Chen Z, Chen J, Meng Y, Chen L, et al. NFE2 induces miR-423-5p to promote gluconeogenesis and hyperglycemia by repressing the hepatic FAM3A-ATP-Akt pathway. Diabetes (2017) 66(7):1819-32. doi: $10.2337 / \mathrm{db} 16-1172$

67. He A, Zhu L, Gupta N, Chang Y, Fang F. Overexpression of micro ribonucleic acid 29, highly up-regulated in diabetic rats, leads to insulin resistance in 3T3-L1 adipocytes. Mol Endocrinol (2007) 21(11):2785-94. doi:10.1210/me. 2007-0167

68. Xu G, Ji C, Song G, Zhao C, Shi C, Song L, et al. miR-26b modulates insulin sensitivity in adipocytes by interrupting the PTEN/PI3K/AKT pathway. Int J Obes (Lond) (2015) 39(10):1523-30. doi:10.1038/ijo.2015.95

69. Costa V, Foti D, Paonessa F, Chiefari E, Palaia L, Brunetti G, et al. The insulin receptor: a new anticancer target for peroxisome proliferator-activated receptor-gamma (PPARgamma) and thiazolidinedione-PPARgamma agonists. Endocr Relat Cancer (2008) 15(1):325-35. doi:10.1677/ERC-07-0226

70. Goldstein BJ. Protein-tyrosine phosphatases: emerging targets for therapeutic intervention in type 2 diabetes and related states of insulin resistance. J Clin Endocrinol Metab (2002) 87(6):2474-80. doi:10.1210/jcem.87.6.8641

71. Xu E, Schwab M, Marette A. Role of protein tyrosine phosphatases in the modulation of insulin signaling and their implication in the pathogenesis 
of obesity-linked insulin resistance. Rev Endocr Metab Disord (2014) 15(1): 79-97. doi:10.1007/s11154-013-9282-4

72. Johnson TO, Ermolieff J, Jirousek MR. Protein tyrosine phosphatase 1B inhibitors for diabetes. Nat Rev Drug Discov (2002) 1(9):696-709. doi:10.1038/ nrd895

73. Qian S, Zhang M, He Y, Wang W, Liu S. Recent advances in the development of protein tyrosine phosphatase $1 \mathrm{~B}$ inhibitors for type 2 diabetes. Future Med Chem (2016) 8(11):1239-58. doi:10.4155/fmc-2016-0064

74. Yang YM, Seo SY, Kim TH, Kim SG. Decrease of microRNA-122 causes hepatic insulin resistance by inducing protein tyrosine phosphatase $1 \mathrm{~B}$, which is reversed by licorice flavonoid. Hepatology (2012) 56(6):2209-20. doi:10.1002/hep.25912

75. Ding XQ, Gu TT, Wang W, Song L, Chen TY, Xue QC, et al. Curcumin protects against fructose-induced podocyte insulin signaling impairment through upregulation of miR-206. Mol Nutr Food Res (2015) 59(12):2355-70. doi:10.1002/mnfr. 201500370

76. Galic S, Sachithanandan N, Kay TW, Steinberg GR. Suppressor of cytokine signalling (SOCS) proteins as guardians of inflammatory responses critical for regulating insulin sensitivity. Biochem J (2014) 461(2):177-88. doi:10.1042/ BJ20140143

77. Ueki K, Kadowaki T, Kahn CR. Role of suppressors of cytokine signaling SOCS- 1 and SOCS-3 in hepatic steatosis and the metabolic syndrome. Hepatol Res (2005) 33(2):185-92. doi:10.1016/j.hepres.2005.09.032

78. Shi H, Cave B, Inouye K, Bjorbaek C, Flier JS. Overexpression of suppressor of cytokine signaling 3 in adipose tissue causes local but not systemic insulin resistance. Diabetes (2006) 55(3):699-707. doi:10.2337/diabetes.55.03.06. $\mathrm{db} 05-0841$

79. Bao L, Fu X, Si M, Wang Y, Ma R, Ren X, et al. MicroRNA-185 targets SOCS3 to inhibit beta-cell dysfunction in diabetes. PLoS One (2015) 10(2): e0116067. doi:10.1371/journal.pone.0116067

80. Li Y, Luo T, Wang L, Wu J, Guo S. MicroRNA-19a-3p enhances the proliferation and insulin secretion, while it inhibits the apoptosis of pancreatic beta cells via the inhibition of SOCS3. Int J Mol Med (2016) 38(5):1515-24. doi:10.3892/ijmm.2016.2748

81. Mohan R, Mao Y, Zhang S, Zhang YW, Xu CR, Gradwohl G, et al. Differentially expressed microRNA-483 confers distinct functions in pancreatic betaand alpha-cells. J Biol Chem (2015) 290(32):19955-66. doi:10.1074/jbc. M115.650705

82. Zhang Y, Mei H, Chang X, Chen F, Zhu Y, Han X. Adipocyte-derived microvesicles from obese mice induce M1 macrophage phenotype through secreted miR-155. J Mol Cell Biol (2016) 8(6):505-17. doi:10.1093/jmcb/mjw040

83. Zhou X, Liu W, Gu M, Zhou H, Zhang G. Helicobacter pylori infection causes hepatic insulin resistance by the C-Jun/miR-203/SOCS3 signaling pathway. J Gastroenterol (2015) 50(10):1027-40. doi:10.1007/s00535-015-1051-6

84. Copps KD, White MF. Regulation of insulin sensitivity by serine/threonine phosphorylation of insulin receptor substrate proteins IRS1 and IRS2. Diabetologia (2012) 55(10):2565-82. doi:10.1007/s00125-012-2644-8

85. Janaki Ramaiah M, Lavanya A, Honarpisheh M, Zarea M, Bhadra U, Bhadra MP. miR-15/16 complex targets p70S6 kinase 1 and controls cell proliferation in MDA-MB-231 breast cancer cells. Gene (2014) 552(2):255-64. doi:10.1016/ j.gene.2014.09.052

86. Chen R, Alvero AB, Silasi DA, Steffensen KD, Mor G. Cancers take their toll - the function and regulation of toll-like receptors in cancer cells. Oncogene (2008) 27(2):225-33. doi:10.1038/sj.onc.1210907

87. Chen R, Alvero AB, Silasi DA, Kelly MG, Fest S, Visintin I, et al. Regulation of IKKbeta by miR-199a affects NF-kappaB activity in ovarian cancer cells. Oncogene (2008) 27(34):4712-23. doi:10.1038/onc.2008.112

88. Zhou HJ, Wang LQ, Xu QS, Fan ZX, Zhu Y, Jiang H, et al. Downregulation of miR-199b promotes the acute spinal cord injury through IKKbeta-NFkappaB signaling pathway activating microglial cells. Exp Cell Res (2016) 349(1):60-7. doi:10.1016/j.yexcr.2016.09.020

89. Farrokhnia F, Aplin JD, Westwood M, Forbes K. MicroRNA regulation of mitogenic signaling networks in the human placenta. J Biol Chem (2014) 289(44):30404-16. doi:10.1074/jbc.M114.587295

90. Deng M, Tang H, Zhou Y, Zhou M, Xiong W, Zheng Y, et al. miR-216b suppresses tumor growth and invasion by targeting KRAS in nasopharyngeal carcinoma. J Cell Sci (2011) 124(Pt 17):2997-3005. doi:10.1242/jcs.085050

91. Liu Y, Zhang M, Qian J, Bao M, Meng X, Zhang S, et al. miR-134 functions as a tumor suppressor in cell proliferation and epithelial-to-mesenchymal transition by targeting KRAS in renal cell carcinoma cells. DNA Cell Biol (2015) 34(6):429-36. doi:10.1089/dna.2014.2629

92. Zhou K, Luo X, Wang Y, Cao D, Sun G. MicroRNA-30a suppresses tumor progression by blocking Ras/Raf/MEK/ERK signaling pathway in hepatocellular carcinoma. Biomed Pharmacother (2017) 93:1025-32. doi:10.1016/ j.biopha.2017.07.029

93. Nigro C, Raciti GA, Leone A, Fleming TH, Longo M, Prevenzano I, et al. Methylglyoxal impairs endothelial insulin sensitivity both in vitro and in vivo. Diabetologia (2014) 57(7):1485-94. doi:10.1007/s00125-014-3243-7

94. Mirra P, Nigro C, Prevenzano I, Procopio T, Leone A, Raciti GA, et al. The role of miR-190a in methylglyoxal-induced insulin resistance in endothelial cells. Biochim Biophys Acta (2017) 1863(2):440-9. doi:10.1016/j. bbadis.2016.11.018

95. Manna P, Jain SK. Phosphatidylinositol-3,4,5-triphosphate and cellular signaling: implications for obesity and diabetes. Cell Physiol Biochem (2015) 35(4):1253-75. doi:10.1159/000373949

96. Farese RV, Sajan MP, Standaert ML. Atypical protein kinase C in insulin action and insulin resistance. Biochem Soc Trans (2005) 33(Pt 2):350-3. doi:10.1042/BST0330350

97. Dyson JM, Fedele CG, Davies EM, Becanovic J, Mitchell CA. Phosphoinositide phosphatases: just as important as the kinases. Subcell Biochem (2012) 58:215-79. doi:10.1007/978-94-007-3012-0_7

98. Vinciguerra M, Sgroi A, Veyrat-Durebex C, Rubbia-Brandt L, Buhler LH, Foti M. Unsaturated fatty acids inhibit the expression of tumor suppressor phosphatase and tensin homolog (PTEN) via microRNA-21 upregulation in hepatocytes. Hepatology (2009) 49(4):1176-84. doi:10.1002/ hep. 22737

99. Ling HY, Hu B, Hu XB, Zhong J, Feng SD, Qin L, et al. miRNA-21 reverses high glucose and high insulin induced insulin resistance in 3T3-L1 adipocytes through targeting phosphatase and tensin homologue. Exp Clin Endocrinol Diabetes (2012) 120(9):553-9. doi:10.1055/s-0032-1311644

100. Song Y, Jin D, Jiang X, Lv C, Zhu H. Overexpression of microRNA-26a protects against deficient beta-cell function via targeting phosphatase with tensin homology in mouse models of type 2 diabetes. Biochem Biophys Res Commun (2018) 495(1):1312-6. doi:10.1016/j.bbrc.2017.11.170

101. Dou L, Wang S, Sui X, Meng X, Shen T, Huang X, et al. miR-301a mediates the effect of IL- 6 on the Akt/GSK pathway and hepatic glycogenesis by regulating PTEN expression. Cell Physiol Biochem (2015) 35(4):1413-24. doi:10.1159/000373962

102. Yu J, Ryan DG, Getsios S, Oliveira-Fernandes M, Fatima A, Lavker RM. MicroRNA-184 antagonizes microRNA-205 to maintain SHIP2 levels in epithelia. Proc Natl Acad Sci U S A (2008) 105(49):19300-5. doi:10.1073/ pnas.0803992105

103. Yu J, Peng H, Ruan Q, Fatima A, Getsios S, Lavker RM. MicroRNA-205 promotes keratinocyte migration via the lipid phosphatase SHIP2. FASEB J (2010) 24(10):3950-9. doi:10.1096/f.10-157404

104. Kowluru A, Matti A. Hyperactivation of protein phosphatase 2A in models of glucolipotoxicity and diabetes: potential mechanisms and functional consequences. Biochem Pharmacol (2012) 84(5):591-7. doi:10.1016/j.bcp. 2012.05.003

105. Ruvolo PP. The broken "off" switch in cancer signaling: PP2A as a regulator of tumorigenesis, drug resistance, and immune surveillance. BBA Clin (2016) 6:87-99. doi:10.1016/j.bbacli.2016.08.002

106. Mavrakis KJ, Wolfe AL, Oricchio E, Palomero T, de Keersmaecker K, McJunkin K, et al. Genome-wide RNA-mediated interference screen identifies miR-19 targets in notch-induced T-cell acute lymphoblastic leukaemia. Nat Cell Biol (2010) 12(4):372-9. doi:10.1038/ncb2037

107. Lashine YA, Salah S, Aboelenein HR, Abdelaziz AI. Correcting the expression of miRNA-155 represses PP2Ac and enhances the release of IL-2 in PBMCs of juvenile SLE patients. Lupus (2015) 24(3):240-7. doi:10.1177/0961203314552117

108. Brognard J, Newton AC. Phlipping the switch on Akt and protein kinase C signaling. Trends Endocrinol Metab (2008) 19(6):223-30. doi:10.1016/j. tem.2008.04.001

109. Andreozzi F, Procopio C, Greco A, Mannino GC, Miele C, Raciti GA, et al. Increased levels of the Akt-specific phosphatase $\mathrm{PH}$ domain leucine-rich repeat protein phosphatase (PHLPP)-1 in obese participants are associated with insulin resistance. Diabetologia (2011) 54(7):1879-87. doi:10.1007/ s00125-011-2116-6 
110. Cozzone D, Frojdo S, Disse E, Debard C, Laville M, Pirola L, et al. Isoformspecific defects of insulin stimulation of Akt/protein kinase B (PKB) in skeletal muscle cells from type 2 diabetic patients. Diabetologia (2008) 51(3):512-21. doi:10.1007/s00125-007-0913-8

111. Beezhold K, Liu J, Kan H, Meighan T, Castranova V, Shi X, et al. miR-190mediated downregulation of PHLPP contributes to arsenic-induced Akt activation and carcinogenesis. Toxicol Sci (2011) 123(2):411-20. doi:10.1093/ toxsci/kfr 188

112. Yu Y, Zhang D, Huang H, Li J, Zhang M, Wan Y, et al. NF-KappaB1 P50 promotes P53 protein translation through miR-190 downregulation of PHLPP1. Oncogene (2014) 33(8):996-1005. doi:10.1038/onc.2013.8

113. Sun X, Lin J, Zhang Y, Kang S, Belkin N, Wara AK, et al. MicroRNA-181b improves glucose homeostasis and insulin sensitivity by regulating endothelial function in white adipose tissue. Circ Res (2016) 118(5):810-21. doi:10.1161/CIRCRESAHA.115.308166

114. Rang Z, Wang ZY, Pang QY, Wang YW, Yang G, Cui F. miR-181a targets PHLPP2 to augment AKT signaling and regulate proliferation and apoptosis in human keloid fibroblasts. Cell Physiol Biochem (2016) 40(3-4):796-806. doi:10.1159/000453139

115. Strotbek M, Schmid S, Sanchez-Gonzalez I, Boerries M, Busch H, Olayioye MA. miR-181 elevates Akt signaling by co-targeting PHLPP2 and INPP4B phosphatases in luminal breast cancer. Int J Cancer (2017) 140(10):2310-20. doi:10.1002/ijc.30661

116. Ding L, Zhang S, Xu M, Zhang R, Sui P, Yang Q. MicroRNA-27a contributes to the malignant behavior of gastric cancer cells by directly targeting $\mathrm{PH}$ domain and leucine-rich repeat protein phosphatase 2. J Exp Clin Cancer Res (2017) 36(1):45. doi:10.1186/s13046-017-0516-2

117. Jiang L, Wang C, Lei F, Zhang L, Zhang X, Liu A, et al. miR-93 promotes cell proliferation in gliomas through activation of PI3K/Akt signaling pathway. Oncotarget (2015) 6(10):8286-99. doi:10.18632/oncotarget.3221

118. Collares RVA, Salgado W Jr, Pretti da Cunha Tirapelli D, dos Santos JS. The expression of LEP, LEPR, IGF1 and IL10 in obesity and the relationship with microRNAs. PLoS One (2014) 9(4):e93512. doi:10.1371/journal. pone.0093512

119. Gu C, Xu Y, Zhang S, Guan H, Song S, Wang X, et al. miR-27a attenuates adipogenesis and promotes osteogenesis in steroid-induced rat BMSCs by targeting PPARgamma and GREM1. Sci Rep (2016) 6:38491. doi:10.1038/ srep38491

120. Chen YH, Heneidi S, Lee JM, Layman LC, Stepp DW, Gamboa GM, et al. miRNA-93 inhibits GLUT4 and is overexpressed in adipose tissue of polycystic ovary syndrome patients and women with insulin resistance. Diabetes (2013) 62(7):2278-86. doi:10.2337/db12-0963

121. He X, Zhang Z, Li M, Li S, Ren L, Zhu H, et al. Expression and role of oncogenic miRNA-224 in esophageal squamous cell carcinoma. BMC Cancer (2015) 15:575. doi:10.1186/s12885-015-1581-6

122. Liao WT, Li TT, Wang ZG, Wang SY, He MR, Ye YP, et al. MicroRNA-224 promotes cell proliferation and tumor growth in human colorectal cancer by repressing PHLPP1 and PHLPP2. Clin Cancer Res (2013) 19(17): 4662-72. doi:10.1158/1078-0432.CCR-13-0244

123. Mei Z, He Y, Feng J, Shi J, Du Y, Qian L, et al. MicroRNA-141 promotes the proliferation of non-small cell lung cancer cells by regulating expression of PHLPP1 and PHLPP2. FEBS Lett (2014) 588(17):3055-61. doi:10.1016/ j.febslet.2014.06.020

124. Du K, Herzig S, Kulkarni RN, Montminy M. TRB3: a tribbles homolog that inhibits Akt/PKB activation by insulin in liver. Science (2003) 300(5625): 1574-7. doi:10.1126/science.1079817

125. Liu J, Wu X, Franklin JL, Messina JL, Hill HS, Moellering DR, et al. Mammalian tribbles homolog 3 impairs insulin action in skeletal muscle: role in glucose-induced insulin resistance. Am J Physiol Endocrinol Metab (2010) 298(3):E565-76. doi:10.1152/ajpendo.00467.2009

126. Liu X, Zhao J, Liu Q, Xiong X, Zhang Z, Jiao Y, et al. MicroRNA-124 promotes hepatic triglyceride accumulation through targeting tribbles homolog 3 . Sci Rep (2016) 6:37170. doi:10.1038/srep37170

127. Zhao M, Chen X, Gao G, Tao L, Wei L. RLEdb: a database of rate-limiting enzymes and their regulation in human, rat, mouse, yeast and E. coli. Cell Res (2009) 19(6):793-5. doi:10.1038/cr.2009.61

128. DeBerardinis RJ, Thompson CB. Cellular metabolism and disease: what do metabolic outliers teach us? Cell (2012) 148(6):1132-44. doi:10.1016/ j.cell.2012.02.032
129. Metallo CM, Vander Heiden MG. Understanding metabolic regulation and its influence on cell physiology. Mol Cell (2013) 49(3):388-98. doi:10.1016/j. molcel.2013.01.018

130. Kozlovsky N, Rudich A, Potashnik R, Ebina Y, Murakami T, Bashan N. Transcriptional activation of the GLUT1 gene in response to oxidative stress in L6 myotubes. J Biol Chem (1997) 272(52):33367-72. doi:10.1074/ jbc. 272.52 .33367

131. Muralimanoharan S, Maloyan A, Myatt L. Mitochondrial function and glucose metabolism in the placenta with gestational diabetes mellitus: role of miR-143. Clin Sci (Lond) (2016) 130(11):931-41. doi:10.1042/ CS20160076

132. Chen B, Tang H, Liu X, Liu P, Yang L, Xie X, et al. miR-22 as a prognostic factor targets glucose transporter protein type 1 in breast cancer. Cancer Lett (2015) 356(2 Pt B):410-7. doi:10.1016/j.canlet.2014.09.028

133. Yuan G, Zhao Y, Wu D, Gao CH. miR-150 up-regulates GLUT1 and increases glycolysis in osteosarcoma cells. Asian Pac J Cancer Prev (2017) 18(4):1127-31. doi:10.22034/APJCP.2017.18.4.1127

134. Leto D, Saltiel AR. Regulation of glucose transport by insulin: traffic control of GLUT4. Nat Rev Mol Cell Biol (2012) 13(6):383-96. doi:10.1038/ nrm3351

135. Smith U. Impaired ('diabetic') insulin signaling and action occur in fat cells long before glucose intolerance - is insulin resistance initiated in the adipose tissue? Int J Obes Relat Metab Disord (2002) 26(7):897-904. doi:10.1038/ sj.ijo.0802028

136. Bjornholm M, Zierath JR. Insulin signal transduction in human skeletal muscle: identifying the defects in type II diabetes. Biochem Soc Trans (2005) 33(Pt 2):354-7. doi:10.1042/BST0330354

137. Bouzakri K, Koistinen HA, Zierath JR. Molecular mechanisms of skeletal muscle insulin resistance in type 2 diabetes. Curr Diabetes Rev (2005) 1(2):167-74. doi:10.2174/1573399054022785

138. Graham TE, Kahn BB. Tissue-specific alterations of glucose transport and molecular mechanisms of intertissue communication in obesity and type 2 diabetes. Horm Metab Res (2007) 39(10):717-21. doi:10.1055/s-2007-985879

139. Yan ST, Li CL, Tian H, Li J, Pei Y, Liu Y, et al. miR-199a is overexpressed in plasma of type 2 diabetes patients which contributes to type 2 diabetes by targeting GLUT4. Mol Cell Biochem (2014) 397(1-2):45-51. doi:10.1007/ s11010-014-2170-8

140. Lu H, Buchan RJ, Cook SA. MicroRNA-223 regulates GLUT4 expression and cardiomyocyte glucose metabolism. Cardiovasc Res (2010) 86(3):410-20. doi:10.1093/cvr/cvq010

141. Chuang TY, Wu HL, Chen CC, Gamboa GM, Layman LC, Diamond MP, et al. MicroRNA-223 expression is upregulated in insulin resistant human adipose tissue. J Diabetes Res (2015) 2015:943659. doi:10.1155/2015/943659

142. Zhou Y, Gu P, Shi W, Li J, Hao Q, Cao X, et al. MicroRNA-29a induces insulin resistance by targeting PPARdelta in skeletal muscle cells. Int J Mol Med (2016) 37(4):931-8. doi:10.3892/ijmm.2016.2499

143. Horie $\mathrm{T}$, Ono $\mathrm{K}$, Nishi $\mathrm{H}$, Iwanaga $\mathrm{Y}$, Nagao $\mathrm{K}$, Kinoshita $\mathrm{M}$, et al. MicroRNA-133 regulates the expression of GLUT4 by targeting KLF15 and is involved in metabolic control in cardiac myocytes. Biochem Biophys Res Commun (2009) 389(2):315-20. doi:10.1016/j.bbrc.2009.08.136

144. Shi Z, Zhao C, Guo X, Ding H, Cui Y, Shen R, et al. Differential expression of microRNAs in omental adipose tissue from gestational diabetes mellitus subjects reveals miR-222 as a regulator of ERalpha expression in estrogeninduced insulin resistance. Endocrinology (2014) 155(5):1982-90. doi:10.1210/ en.2013-2046

145. Lee H, Jee Y, Hong K, Hwang GS, Chun KH. MicroRNA-494, upregulated by tumor necrosis factor-alpha, desensitizes insulin effect in $\mathrm{C} 2 \mathrm{C} 12$ muscle cells. PLoS One (2013) 8(12):e83471. doi:10.1371/journal.pone.0083471

146. Vestergaard H, Bjorbaek C, Hansen T, Larsen FS, Granner DK, Pedersen O. Impaired activity and gene expression of hexokinase II in muscle from noninsulin-dependent diabetes mellitus patients. J Clin Invest (1995) 96(6): 2639-45. doi:10.1172/JCI118329

147. Park SY, Lee JH, Ha M, Nam JW, Kim VN. miR-29 miRNAs activate P53 by targeting P85 alpha and CDC42. Nat Struct Mol Biol (2009) 16(1):23-9. doi:10.1038/nsmb.1533

148. Mathupala SP, Ko YH, Pedersen PL. Hexokinase II: cancer's double-edged sword acting as both facilitator and gatekeeper of malignancy when bound to mitochondria. Oncogene (2006) 25(34):4777-86. doi:10.1038/ sj.onc. 1209603 
149. Wu J, Hu L, Wu F, Zou L, He T. Poor prognosis of hexokinase 2 overexpression in solid tumors of digestive system: a meta-analysis. Oncotarget (2017) 8(19):32332-44. doi:10.18632/oncotarget.15974

150. Fang R, Xiao T, Fang Z, Sun Y, Li F, Gao Y, et al. MicroRNA-143 (miR-143) regulates cancer glycolysis via targeting hexokinase 2 gene. J Biol Chem (2012) 287(27):23227-35. doi:10.1074/jbc.M112.373084

151. Zhao S, Liu H, Liu Y, Wu J, Wang C, Hou X, et al. miR-143 inhibits glycolysis and depletes stemness of glioblastoma stem-like cells. Cancer Lett (2013) 333(2):253-60. doi:10.1016/j.canlet.2013.01.039

152. Sun X, Zhang L. MicroRNA-143 suppresses oral squamous cell carcinoma cell growth, invasion and glucose metabolism through targeting hexokinase 2. Biosci Rep (2017) 37:3. doi:10.1042/BSR20160404

153. Irwin DM, Tan H. Evolution of glucose utilization: glucokinase and glucokinase regulator protein. Mol Phylogenet Evol (2014) 70:195-203. doi:10.1016/ j.ympev.2013.09.016

154. Bae JS, Kim TH, Kim MY, Park JM, Ahn YH. Transcriptional regulation of glucose sensors in pancreatic beta-cells and liver: an update. Sensors (Basel) (2010) 10(5):5031-53. doi:10.3390/s100505031

155. Ofori JK, Salunkhe VA, Bagge A, Vishnu N, Nagao M, Mulder H, et al. Elevated miR-130a/miR130b/miR-152 expression reduces intracellular ATP levels in the pancreatic beta cell. Sci Rep (2017) 7:44986. doi:10.1038/ srep44986

156. Vinod M, Patankar JV, Sachdev V, Frank S, Graier WF, Kratky D, et al. miR-206 is expressed in pancreatic islets and regulates glucokinase activity. Am J Physiol Endocrinol Metab (2016) 311(1):E175-85. doi:10.1152/ ajpendo.00510.2015

157. Nakamura A, Terauchi Y. Present status of clinical deployment of glucokinase activators. J Diabetes Investig (2015) 6(2):124-32. doi:10.1111/ jdi.12294

158. Du JY, Wang LF, Wang Q, Yu LD. miR-26b inhibits proliferation, migration, invasion and apoptosis induction via the downregulation of 6phosphofructo-2-kinase/fructose-2,6-bisphosphatase-3 driven glycolysis in osteosarcoma cells. Oncol Rep (2015) 33(4):1890-8. doi:10.3892/or. 2015.3797

159. Karbiener M, Pisani DF, Frontini A, Oberreiter LM, Lang E, Vegiopoulos A, et al. MicroRNA-26 family is required for human adipogenesis and drives characteristics of brown adipocytes. Stem Cells (2014) 32(6):1578-90. doi:10.1002/stem.1603

160. Liang L, Li Q, Huang L, Li D, Li X. SIRT3 binds to and deacetylates mitochondrial pyruvate carrier 1 to enhance its activity. Biochem Biophys Res Commun (2015) 468(4):807-12. doi:10.1016/j.bbrc.2015.11.036

161. Kumashiro N, Beddow SA, Vatner DF, Majumdar SK, Cantley JL, GuebreEgziabher F, et al. Targeting pyruvate carboxylase reduces gluconeogenesis and adiposity and improves insulin resistance. Diabetes (2013) 62(7): 2183-94. doi:10.2337/db12-1311

162. Hue L, Taegtmeyer H. The randle cycle revisited: a new head for an old hat. Am J Physiol Endocrinol Metab (2009) 297(3):E578-91. doi:10.1152/ ajpendo.00093.2009

163. Chen B, Liu Y, Jin X, Lu W, Liu J, Xia Z, et al. MicroRNA-26a regulates glucose metabolism by direct targeting PDHX in colorectal cancer cells. BMC Cancer (2014) 14:443. doi:10.1186/1471-2407-14-443

164. Fu X, Dong B, Tian Y, Lefebvre P, Meng Z, Wang X, et al. MicroRNA-26a regulates insulin sensitivity and metabolism of glucose and lipids. J Clin Invest (2015) 125(6):2497-509. doi:10.1172/JCI75438

165. Icli B, Nabzdyk CS, Lujan-Hernandez J, Cahill M, Auster ME, Wara AK, et al. Regulation of impaired angiogenesis in diabetic dermal wound healing by microRNA-26a. J Mol Cell Cardiol (2016) 91:151-9. doi:10.1016/j. yjmcc.2016.01.007

166. Sugden MC, Holness MJ. Recent advances in mechanisms regulating glucose oxidation at the level of the pyruvate dehydrogenase complex by PDKS. Am J Physiol Endocrinol Metab (2003) 284(5):E855-62. doi:10.1152/ ajpendo.00526.2002

167. Sugden MC, Holness MJ. Mechanisms underlying regulation of the expression and activities of the mammalian pyruvate dehydrogenase kinases. Arch Physiol Biochem (2006) 112(3):139-49. doi:10.1080/13813450600935263
168. Gopal K, Saleme B, Al Batran R, Aburasayn H, Eshreif A, Ho KL, et al. FoxO1 regulates myocardial glucose oxidation rates via transcriptional control of pyruvate dehydrogenase kinase 4 expression. Am J Physiol Heart Circ Physiol (2017) 313(3):H479-90. doi:10.1152/ajpheart.00191.2017

169. Goodpaster BH, Sparks LM. Metabolic flexibility in health and disease. Cell Metab (2017) 25(5):1027-36. doi:10.1016/j.cmet.2017.04.015

170. Kim YI, Lee FN, Choi WS, Lee S, Youn JH. Insulin regulation of skeletal muscle PDK4 mRNA expression is impaired in acute insulin-resistant states. Diabetes (2006) 55(8):2311-7. doi:10.2337/db05-1606

171. Zhang S, Hulver MW, McMillan RP, Cline MA, Gilbert ER. The pivotal role of pyruvate dehydrogenase kinases in metabolic flexibility. Nutr Metab (Lond) (2014) 11(1):10. doi:10.1186/1743-7075-11-10

172. Rosa G, Di Rocco P, Manco M, Greco AV, Castagneto M, Vidal H, et al. Reduced PDK4 expression associates with increased insulin sensitivity in postobese patients. Obes Res (2003) 11(2):176-82. doi:10.1038/oby.2003.28

173. Barres R, Kirchner H, Rasmussen M, Yan J, Kantor FR, Krook A, et al. Weight loss after gastric bypass surgery in human obesity remodels promoter methylation. Cell Rep (2013) 3(4):1020-7. doi:10.1016/j.celrep.2013. 03.018

174. Barres R, Yan J, Egan B, Treebak JT, Rasmussen M, Fritz T, et al. Acute exercise remodels promoter methylation in human skeletal muscle. Cell Metab (2012) 15(3):405-11. doi:10.1016/j.cmet.2012.01.001

175. Yamane K I, Indalao L, Chida J, Yamamoto Y, Hanawa M, Kido H. Diisopropylamine dichloroacetate, a novel pyruvate dehydrogenase kinase 4 inhibitor, as a potential therapeutic agent for metabolic disorders and multiorgan failure in severe influenza. PLoS One (2014) 9(5):e98032. doi:10.1371/ journal.pone.0098032

176. Yount EA, Felten SY, O'Connor BL, Peterson RG, Powell RS, Yum MN, et al. Comparison of the metabolic and toxic effects of 2-chloropropionate and dichloroacetate. J Pharmacol Exp Ther (1982) 222(2):501-8.

177. Stacpoole PW, Henderson GN, Yan Z, Cornett R, James MO. Pharmacokinetics, metabolism and toxicology of dichloroacetate. Drug Metab Rev (1998) 30(3):499-539. doi:10.3109/03602539808996323

178. Han H, Li W, Shen H, Zhang J, Zhu Y, Li Y. MicroRNA-129-5p, a c-Myc negative target, affects hepatocellular carcinoma progression by blocking the Warburg effect. J Mol Cell Biol (2016) 8(5):400-10. doi:10.1093/jmcb/ mjw010

179. Karunakaran D, Thrush AB, Nguyen MA, Richards L, Geoffrion M, Singaravelu R, et al. Macrophage mitochondrial energy status regulates cholesterol efflux and is enhanced by anti-miR33 in atherosclerosis. Circ Res (2015) 117(3):266-78. doi:10.1161/CIRCRESAHA.117.305624

180. Song K, Kwon H, Han C, Zhang J, Dash S, Lim K, et al. Active glycolytic metabolism in CD133(+) hepatocellular cancer stem cells: regulation by miR-122. Oncotarget (2015) 6(38):40822-35. doi:10.18632/oncotarget. 5812

181. Zhang D, Li Y, Yao X, Wang H, Zhao L, Jiang H, et al. miR-182 regulates metabolic homeostasis by modulating glucose utilization in muscle. Cell Rep (2016) 16(3):757-68. doi:10.1016/j.celrep.2016.06.040

182. Hatziapostolou M, Polytarchou C, Iliopoulos D. miRNAs link metabolic reprogramming to oncogenesis. Trends Endocrinol Metab (2013) 24(7):36173. doi:10.1016/j.tem.2013.03.002

Conflict of Interest Statement: The authors declare that the research was conducted in the absence of any commercial or financial relationships that could be construed as a potential conflict of interest.

The reviewer RI and handling editor declared their shared affiliation.

Copyright (c) 2018 Mirra, Nigro, Prevenzano, Leone, Raciti, Formisano, Beguinot and Miele. This is an open-access article distributed under the terms of the Creative Commons Attribution License (CC BY). The use, distribution or reproduction in other forums is permitted, provided the original author(s) and the copyright owner are credited and that the original publication in this journal is cited, in accordance with accepted academic practice. No use, distribution or reproduction is permitted which does not comply with these terms. 